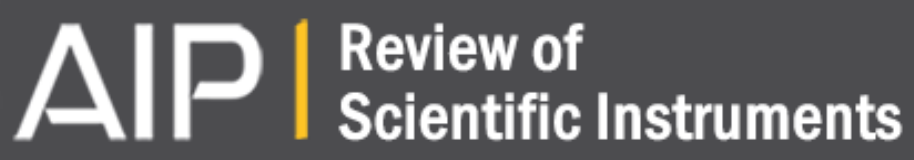

Experimental validation of a newly designed 6 degrees of freedom scanning laser head: Application to three-dimensional beam structure

D. Di Maio and E. Copertaro

Citation: Review of Scientific Instruments 84, 121708 (2013); doi: 10.1063/1.4845535

View online: http://dx.doi.org/10.1063/1.4845535

View Table of Contents: http://scitation.aip.org/content/aip/journal/rsi/84/12?ver=pdfcov

Published by the AIP Publishing

\section{Articles you may be interested in}

Development of a scanning head for laser Doppler vibrometry (LDV) using dual optical wedges

Rev. Sci. Instrum. 84, 121704 (2013); 10.1063/1.4845555

Surface wave measurements using a single continuously scanning laser Doppler vibrometer: Application to elastography

J. Acoust. Soc. Am. 133, 1245 (2013); 10.1121/1.4789929

Experimental validation of a newly designed 6-DoF scanning laser head

AIP Conf. Proc. 1457, 242 (2012); 10.1063/1.4730563

Determination and visualization of the wave propagation on solid surfaces using a single head laser vibrometer AIP Conf. Proc. 1433, 259 (2012); 10.1063/1.3703184

\section{SHIMADZU Powerful, Multi-functional UV-Vis-NIR and Excellence in Science FTIR Spectrophotometers}

Providing the utmost in sensitivity, accuracy and resolution for a wide array of applications in materials characterization and nanotechnology research

- Photovoltaics - Ceramics

- Polymers

- FPDs

- Thin films

- Coatings

- Paints/inks

- Semiconductors

Click here to learn more
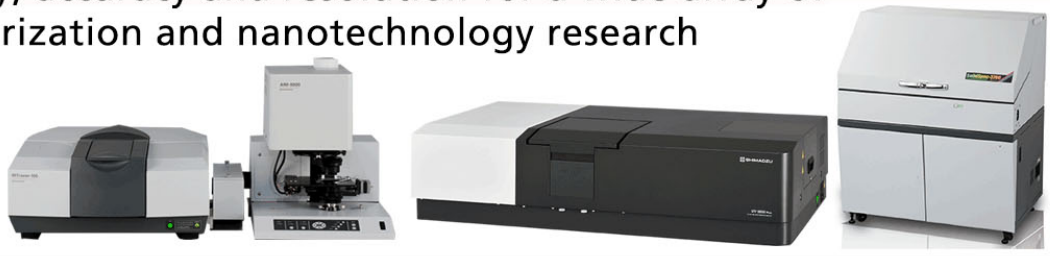


\title{
Experimental validation of a newly designed 6 degrees of freedom scanning laser head: Application to three-dimensional beam structure
}

\author{
D. Di Maio ${ }^{1, a)}$ and E. Copertaro ${ }^{2}$ \\ ${ }^{1}$ Department of Mechanical Engineering, University of Bristol, Queen's Building, University Walk, \\ Bristol BS8 1TR, United Kingdom \\ ${ }^{2}$ Università Politecnica delle Marche, P.zza Roma 22, 60121 Ancona, Italy
}

(Received 24 May 2013; accepted 9 September 2013; published online 30 December 2013)

\begin{abstract}
A new scanning laser head is designed to use single Laser Doppler Vibrometer (LDV) for performing measurements up to 6 degrees of freedom (DOF) at a target. The scanning head is supported by a rotating hollow shaft, which allows the laser beam to travel up to the scanning head from an opposite direction where an LDV is set up. The scanning head is made of a set of two mirrors, which deflects the laser beam with an angle so that the rotation of the scanning head produces a conical scan. When measurements are performed at the focal point of the conical scan then three translational vibration components can be measured, otherwise the very small circle scan, before and after the focal point, can measure up to 6 degrees of freedom, including three translations and three rotations. This paper presents the 6DOF scanning head and the measurements of 3D operational deflection shapes of a test structure. (C) 2013 AIP Publishing LLC. [http://dx.doi.org/10.1063/1.4845535]
\end{abstract}

\section{INTRODUCTION}

The dynamic response of each point on a structure consists of 6 degrees of freedom (DOF), including three translational and three rotational motions. Depending on the excitation direction and on the symmetry of the structure, one or two of the DOFs will appear to be predominant during a measurement, but for a highly accurate model validation more DOFs may be required at specific positions on the test structure. Triaxial accelerometers, which provide information about the three translational degrees of freedom, are available for this purpose, or a three-dimensional Electronic Speckle Pattern Interferometry (ESPI) approach with three light sources can be used to measure the three translational vibration components of a structure. ${ }^{1}$ Commercial 3D Laser Doppler Vibrometer (LDV) systems are also available, and these allow the fast and accurate contact-less measurement of the translational DOFs. Single-point LDVs can be arranged in a 3D-LDV system, where the velocities at a point are being measured by three laser sources from slightly different directions such that the measured data can be processed to obtain the three translational DOFs (Polytec, CLV-3D Compact 3D Laser Vibrometer). The latest developments are the very expensive 3D Scanning Laser Doppler Vibrometer (SLDV) systems. The combination of three slightly separated scanning laser heads enables a three-dimensional full-field measurement of a structure (Polytec, PSV-500-3D Scanning Vibrometer). The threedimensional LDV methods focus on the translational DOFs, and neglect the rotational DOFs around a point. Digital Image Correlation (DIC) is another non-contact measurement technique often used for measurement of deflection shapes. It was initially developed for aerial mapping and then applied for measurement of strains caused by static loading. Over the

\footnotetext{
a) Author to whom correspondence should be addressed. Electronic mail: dario.dimaio@ bristol.ac.uk. Tel.: +441173315907. Fax: +44 (0)11795 45666 .
}

years, with the development of faster cameras, the DIC approach was also used for dynamic testing. Warren et al. ${ }^{2}$ produced a paper which compares vibration measurements obtained using conventional accelerometers, SLDV, and DIC methods. It is clear that the use of the latter one increases the number of measurement points very much and these being captured at the same time make the measurement very time efficient. The SLDV can capture the same number of points but sequentially and therefore increasing the acquisition times. Helfrick et al. ${ }^{3}$ produced a paper about the 3D full-field approach using the DIC measurement method. The technique is definitely an alternative for vibration measurements performed by SLDV systems but some disadvantages are also presented. Such as, (i) the highest measurable frequency is largely dictated by the cameras used for the tests, (ii) the out of plane resolution degrades as the frame rate increases, and (iii) photographic aliasing is also a problem. Wang et al. ${ }^{4}$ present a work where DIC is used for full-field vibration measurements. The authors states that this measurement technique produces large amount of redundant data points, but the application of image processing using functional transformation enables the extraction of a small number of shape features without any significant loss of information from raw DIC data. One clear difference between the use of LDV and DIC is that the latter one requires a surface treatment (application of speckle patterns), which is not always possible to apply to test structures. Single point LDV can be used for measuring vibrations along the direction of the laser beam. The three translations can only be captured if the laser beam can perform a continuous scanning at a target point. Stanbridge et al..$^{5-7}$ introduced a Continuous Scanning Laser Doppler Vibrometer (CSLDV) method that allowed the determination of 5 DOFs at a point on a structure.

A technique for measuring five DOFs at a point with a single setup is to perform a conical scan, which is not focused on the measurement point (or very small area). A 


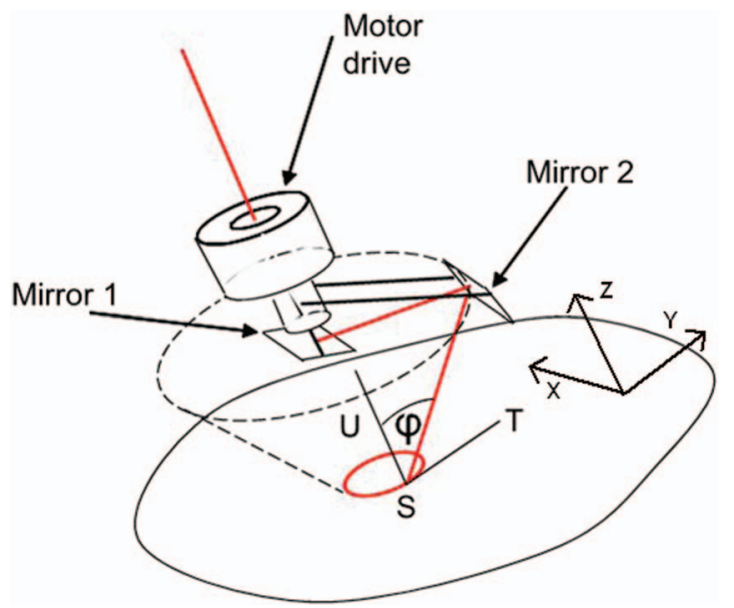

FIG. 1. First schematic drawing of the 6DOF scanner. Reprinted with permission from AIP Conf. Proc. 1457, 242 (2012). Copyright 2012 American Institute of Physics. ${ }^{10}$

circular-conical scan can be performed by moving the cone, traced in space by the scanning laser, either forward or backward to intercept the measurement plane with a small circle rather than with a point. When a measurement is performed as explained then the real and imaginary components (both amplitude and phase) of three translational and rotational components are included in LDV output signal. A single circularconical scan does not provide enough information to solve all the unknown variables and a second measurement is required to overcome the shortage of information. The first one can be performed in the backward plane and the second one in the forward plane, but for both cases the laser must describe circles with the same radius. The scan diameter of the circles must be small enough, so that the illuminated area can be assumed to be rigid. The difference between the two measurements is a shift of $\pi$ in the phase of the components of rotation, because the laser beam travels in different directions depending on the scanning plane.

The measurement of the rotation around the axis, normal to the target, requires that the laser beam must be inclined by an angle, $\varphi$, from the radial direction of the scanned circle, as shown in Figure 1. Therefore, the measurement can be performed by using a set of mirrors deflecting the laser beam with a specific angle. The first design concept of such a laser scanner was proposed by Stanbridge who suggested a laser beam deflected by two mirrors attached to a rotating scanning head. ${ }^{5-7}$ The suggested mechanical fixture allows the laser beam to trace a circle with an angular incidence, $\varphi$, on the vibrating surface so that the rotational vibration can be measured.

\section{MEASUREMENT OF 6 DEGREES OF FREEDOM AT MEASUREMENT POINT}

A single point LDV is able to measure all six degrees of freedom if a scanning head is designed as suggested in Figure 1. The laser must therefore be inclined with an angle 0 $<\varphi<\pi / 2$ from the normal to the plane of the small circle, to allow the measurement of the in-plane rotation. The angle $\beta$,

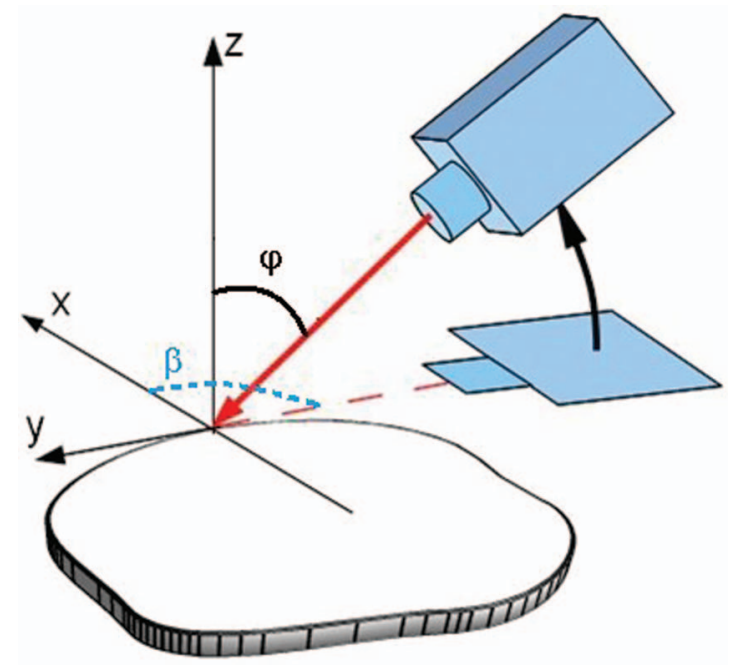

FIG. 2. Angular inclination of the laser beam.

as shown in Figure 2, is equal to $\pi / 2$ and so all cosine terms are equal to 1 , this is the reason why it will not be present in the mathematical descriptions; see Ref. 8 for additional information.

This inclination of the laser beam means that additional vibration information is now added to the LDV signal. The laser picks up components of all six DOFs and the resulting total laser velocity, $V_{L D V}$, becomes

$$
\begin{aligned}
V_{L D V}= & {\left[\Theta_{z}(t) R+V_{x}(t) \cos \left(\Omega_{0} t\right)+V_{y}(t) \sin \left(\Omega_{0} t\right)\right] } \\
& \sin (\varphi)+\left[V_{z}(t)+\Theta_{x}(t) R \cos \left(\Omega_{0} t\right)\right. \\
& \left.+\Theta_{y}(t) R \sin \left(\Omega_{0} t\right)\right] \cos \varphi .
\end{aligned}
$$

From Eq. (1) it can be seen that the in-plane translation components, $\mathrm{V}_{\mathrm{x}}$ and $\mathrm{V}_{\mathrm{y}}$, and the out-of-plane rotational components, $\Theta_{\mathrm{x}}$ and $\Theta_{\mathrm{y}}$, will be modulated by the scan frequency, $\Omega_{0}$, whereas the out of plane translation, $V_{z}$, and the in-plane rotation, $\Theta_{z}$, are not modulated. The spectrum of the resulting LDV signal will contain a central peak at the excitation frequency, $\omega$, and two additional sidebands at $\left(\omega-\Omega_{0}\right)$ and $\left(\omega+\Omega_{0}\right)$.

The translation and rotation of the laser signal vary harmonically in time with the excitation frequency, $\omega=2 \pi f_{e}$. Substituting the time-dependent velocity terms in Eq. (1) with their real and imaginary components, $V_{R e} \cos (\omega t)$ and $V_{I m} \sin (\omega t)$, rearranging the results, and applying Werner's formula lead to

$$
\begin{aligned}
V_{L D V}= & \Re_{\omega} \cos (\omega t)+\Im_{\omega} \sin (\omega t)+\Re_{\omega-\Omega_{0}} \cos \left(\left(\omega-\Omega_{0}\right) t\right) \\
& +\Im_{\omega-\Omega_{0}} \sin \left(\left(\omega-\Omega_{0}\right) t\right)+\Re_{\omega+\Omega_{0}} \cos \left(\left(\omega+\Omega_{0}\right) t\right) \\
& +\Im_{\omega+\Omega_{0}} \sin \left(\left(\omega+\Omega_{0}\right) t\right) .
\end{aligned}
$$

One of the possible approaches for measuring and extracting all six degrees of freedom consists in two inclined tangential scans. (i) one with an angle of incidence of the laser beam defined positive (P), as shown in Figure 3(a), and (ii) second with the laser beam inclined with a different incident angle or negative (N), as shown in Figure 3(b); specifically, the tilt 

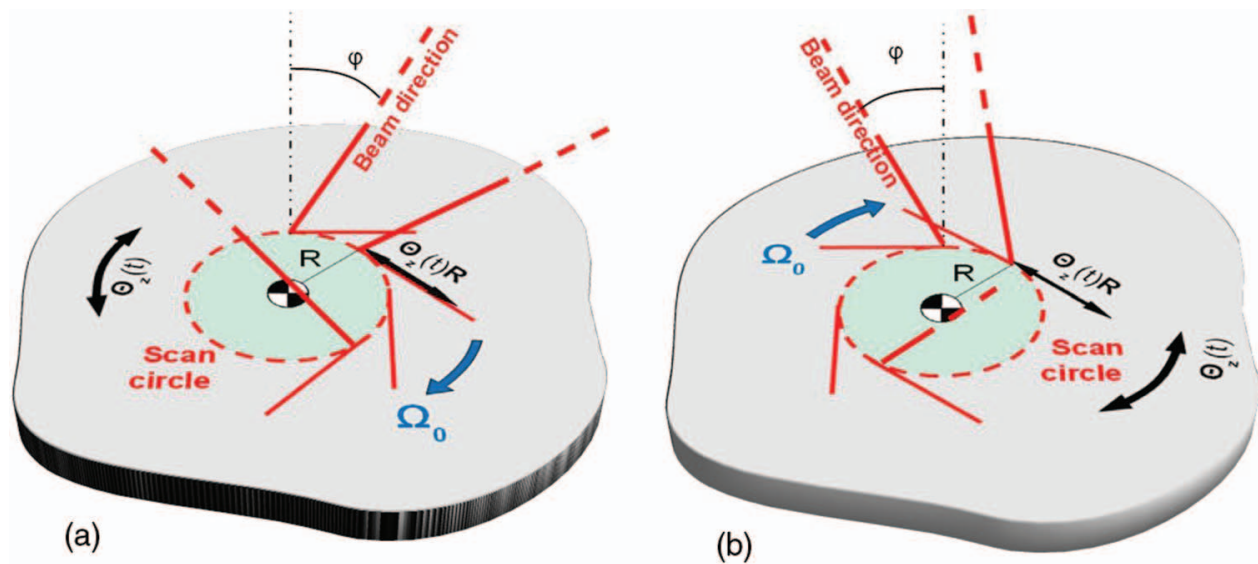

FIG. 3. (a) Positive and (b) negative angular positions during scanning.

angle $\varphi$ shall have either a negative or positive inclination on the plane tangent to the circle.

This leads to acquire two LDV output signals but where $\Theta_{z}, V_{x}$, and $V_{y}$ are shifted of $\pi$ with respect to the first acquisition:

$$
\begin{aligned}
V_{L D V_{P}}= & {\left[\Theta_{z}(t) R+V_{x}(t) \cos \left(\Omega_{0} t\right)+V_{y}(t) \sin \left(\Omega_{0} t\right)\right] \sin (\varphi) } \\
& +\left[V_{z}(t)+\Theta_{x}(t) R \cos \left(\Omega_{0} t\right)+\Theta_{y}(t) R \sin \left(\Omega_{0} t\right)\right] \cos \varphi,
\end{aligned}
$$

$$
\begin{aligned}
V_{L D V_{N}}= & {\left[-\Theta_{z}(t) R-V_{x}(t) \cos \left(\Omega_{0} t\right)-V_{y}(t) \sin \left(\Omega_{0} t\right)\right] \sin (\varphi) } \\
& +\left[V_{z}(t)+\Theta_{x}(t) R \cos \left(\Omega_{0} t\right)+\Theta_{y}(t) R \sin \left(\Omega_{0} t\right)\right] \cos \varphi .
\end{aligned}
$$

Equations (3) and (4) lead to the following (where the suffix "P" indicates data from the first scan with a "positive" tilt angle and "N" data from the second scan with "negative" tilt angle):

$$
\begin{aligned}
& V_{z R e}=\frac{\Re_{\omega_{-} \mathrm{P}}+\Re_{\omega_{-} \mathrm{N}}}{\cos (\varphi)}, \\
& V_{z I m}=\frac{\Im_{\omega_{-} \mathrm{P}}+\Im_{\omega_{-} \mathrm{N}}}{\cos (\varphi)}, \\
& \mathrm{V}_{\mathrm{xRe}}=\frac{\Re_{\omega-\Omega \mathrm{o} \_\mathrm{P}}+\Re_{\omega+\Omega \mathrm{o} \_\mathrm{P}}+\Re_{\omega-\Omega \mathrm{o} \_\mathrm{N}}+\Re_{\omega+\Omega \mathrm{o} \_\mathrm{N}}}{2 \sin (\phi)}, \\
& \mathrm{V}_{\mathrm{xIm}}=\frac{\mathfrak{I}_{\omega-\Omega \mathrm{o} \_\mathrm{P}}+\Im_{\omega+\Omega \mathrm{o} \_\mathrm{P}}+\Im_{\omega-\Omega \mathrm{o} \_\mathrm{N}}+\Im_{\omega+\Omega \mathrm{o} \_\mathrm{N}}}{2 \sin (\phi)}, \\
& \mathrm{V}_{\mathrm{yRe}}=\frac{\Im_{\omega+\Omega 0} \_\mathrm{P}-\Im_{\omega-\Omega 0} \mathrm{P}+\Im_{\omega+\Omega 0} \_\mathrm{N}-\Im_{\omega-\Omega \mathrm{o} \_\mathrm{N}}}{2 \sin (\phi)}, \\
& \mathrm{V}_{\mathrm{yIm}}=\frac{\Re_{\omega-\Omega \mathrm{o} \_\mathrm{P}}-\Re_{\omega+\Omega \mathrm{o} \_\mathrm{P}}+\Re_{\omega-\Omega \mathrm{o} \_\mathrm{N}}-\Re_{\omega+\Omega \mathrm{o} \_\mathrm{N}}}{2 \sin (\phi)},
\end{aligned}
$$

$$
\begin{aligned}
& \Theta_{\mathrm{zRe}}=\frac{\Re_{\omega_{\perp} \mathrm{P}}-\Re_{\omega_{-} \mathrm{N}}}{\mathrm{R} \sin (\phi)}, \\
& \Theta_{\mathrm{zIm}}=\frac{\mathfrak{I}_{\omega_{-} \mathrm{P}}-\Im_{\omega_{-} \mathrm{N}}}{\mathrm{R} \sin (\phi)},
\end{aligned}
$$

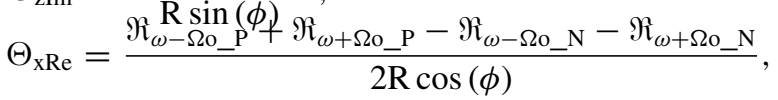

$$
\begin{aligned}
& \Theta_{\mathrm{xIm}}=\frac{\mathfrak{\Im}_{\omega-\Omega \mathrm{o} \_\mathrm{P}}+\Im_{\omega+\Omega \mathrm{o} \_\mathrm{P}}-\Im_{\omega-\Omega \mathrm{o} \_\mathrm{N}}-\widetilde{\Im}_{\omega+\Omega \mathrm{o} \_\mathrm{N}}}{2 \mathrm{R} \cos (\phi)}, \\
& \Theta_{\mathrm{yIm}}=\frac{\Re_{\omega-\Omega \mathrm{o} \_\mathrm{P}}-\Re_{\omega+\Omega \mathrm{o} \_\mathrm{P}}-\Re_{\omega-\Omega \mathrm{o} \_\mathrm{N}}+\Re_{\omega+\Omega \mathrm{o} \_\mathrm{N}}}{2 \mathrm{R} \cos (\phi)}, \\
& \Theta_{\mathrm{yRe}}=\frac{\mathfrak{I}_{\omega+\Omega \mathrm{o} \_\mathrm{P}}-\Im_{\omega-\Omega \mathrm{o} \_\mathrm{P}}-\Im_{\omega+\Omega \mathrm{o} \_\mathrm{N}}+\mathfrak{\Im}_{\omega-\Omega \mathrm{o} \_\mathrm{N}}}{2 \mathrm{R} \cos (\phi)} .
\end{aligned}
$$

It is useful to remind that comparison of measured data requires knowledge of the excitation phase.

The in-plane vibration is contained in the central peak which contains the summation of the in-plane rotation, $\Theta_{z}$, and the out-of-plane vibration, $V_{z}$. The phase between the outof-plane translation and the in-plane rotation must be considered as well, since the resulting output signal magnitude is a summation of both translational and rotational components and thereby larger or smaller according to the phase of the two motions. After several mathematical manipulations the final in-plane rotational component can be calculated as

$$
\Theta_{z 0}=\frac{A_{\omega}-V_{z 0} \cos (\varphi)}{R \sin (\varphi)} .
$$

For an out of phase motion the in-plane rotation becomes

$$
\Theta_{z 0}=\frac{A_{\omega}+V_{z 0} \cos (\varphi)}{R \sin (\varphi)} .
$$

The amplitude of the centre peak in the frequency domain is

$$
A_{\omega}=\sqrt{\Re_{\omega}^{2}+\Im_{\omega}^{2}}==\sqrt{V_{z 0}^{2} \cos ^{2}(\varphi)+\Theta_{z 0}^{2} R^{2} \sin ^{2}(\varphi)+2\left(V_{z R e} \Theta_{z R e}+V_{z I m} \Theta_{z I m}\right) R \cos (\varphi) \sin (\varphi)},
$$


where $\mathrm{V}_{\mathrm{z} 0}$ and $\Theta_{\mathrm{z} 0}$ are the unknown amplitudes of the out-ofplane translation and the in-plane rotation, respectively. The extraction of the in-plane rotation component, $\Theta_{\mathrm{z} 0}$, from the central peak in the spectrum, $A_{\omega}$, requires knowledge of the out-of-plane translational motion, $V_{z 0}$, and the phase shift between the two signals, which can either be equal to zero or $\pi$. The full mathematical description of this section is available in Ref. 8.

\section{6DOF SCANNING DEVICE}

The sketch presented in Figure 1 shows the original idea of scanning head which was then designed and made. ${ }^{8}$ This section presents and compares the two manufactured scanning devices: (i) a prototype used for measuring the in-plane rotational vibrations and (ii) the development of a more compact and robust scanner for practical engineering applications.

The first type, or prototype, was designed based on a set of criteria to ensure that the setup would be able to measure the required data. The scanner must generate circular scans with a small enough radius so as to allow the assumption of rigid body motion of the scanned surface. Clearly, this assumption depends on the frequency bandwidth, size of a test structure, and therefore small circle is a relative assumption. Two special laser mirrors must be used to avoid uncertainty in the deflection of the laser beam. The mirror alignment system must provide the possibility for making an accurate inclination of one mirror with an angle towards the surface normal, and the second mirror with an angle towards the radial direction to allow an adjustable setup of the scanning laser. A practical approach is required to transfer the laser beam to the rotating head, and to allow an accurate alignment of the beam and mirror system. The rotation speed of the head must be monitored. Several configurations of the design were considered during the development, leading to the final version shown in Figure 4.

This scanning head is able to control the laser beam in several directions by tilting the two mirrors' supports independently; this allows a wide range of setup configurations. The new scanning head shown in Figure 4 was installed on a rotating hollow shaft, which allowed the laser beam from a fibre optic LDV system (Polytec OFV-552 Fibre Vibrometer) to reach the mirrors. An electric motor was used to drive the hollow shaft and the scanning head. The shaft rotation speed

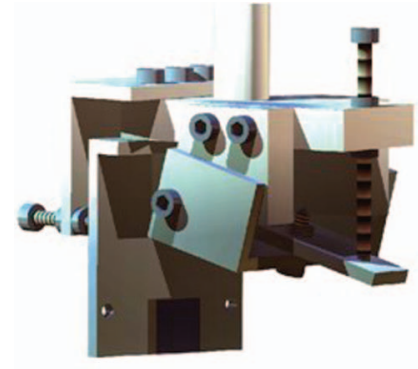

(a)

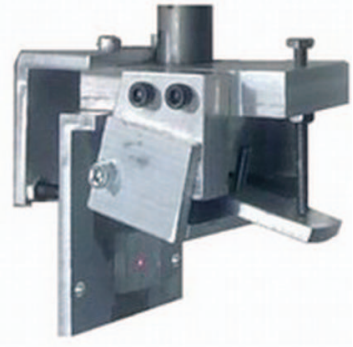

(b)
FIG. 4. 6DOF scanning head. (a) Solid model and (b) manufacture. Reprinted with permission from AIP Conf. Proc. 1457, 242 (2012). Copyright 2012 American Institute of Physics. ${ }^{10}$

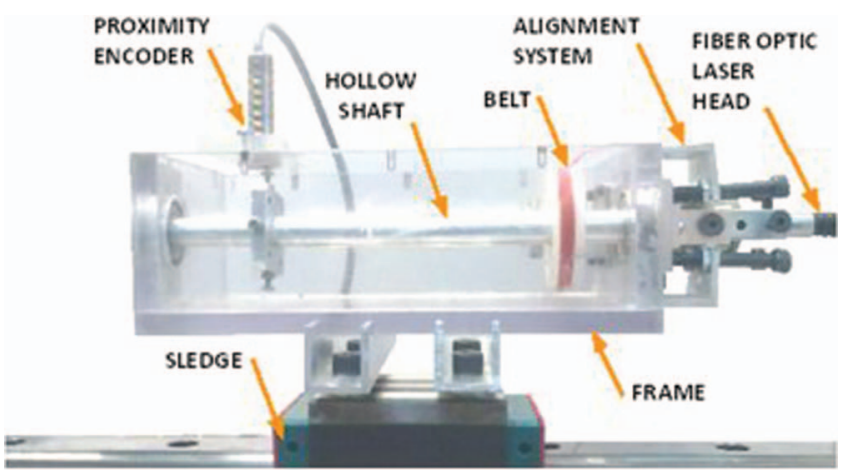

FIG. 5. Scanning laser head assembly. Reprinted with permission from AIP Conf. Proc. 1457, 242 (2012). Copyright 2012 American Institute of Physics. ${ }^{10}$

was accurately monitored with a proximity sensor, since any speed fluctuation caused by the transmission between the motor and the shaft would lead to a variable scan rate and compromise the measurement and post-processing. All components were installed inside a box, which was mounted on a rail to move the entire scanning system backwards and forwards. Figure 5 shows the full assembly for supporting the scanning head.

The prototype was used for proving the ability of measuring in-plane rotational vibrations, but it was practically unable of performing measurements for more realistic and engineering focussed applications. In fact, the size of the full assembly was rather big for scanning a set of measurement points on a test structure. The alignment of the laser beam was also quite difficult to achieve and so it was decided to design a new assembly, which could be more compact and reliable for practical applications.

Figure 6 shows the design drawing of the 6DOF scanning device. The full assembly is very compact and much smaller than its predecessor. The solid metallic body (3) supports a small electric motor (1) and the scanning head (2). An alignment system (4) is connected to the solid body by a set of screws, which allows the alignment of the head of the fibre optic laser probe. The laser beam can travel through the shaft, which is rotated by a rubber band connecting the pulley of the electric motor and the scanning head.

Figure 7(a) shows the degrees of freedom for aligning the laser probe and the two mirrors, one of which is fixed (B) with an angle of $22.5^{\circ}$ and the other one (B) can be slightly adjusted around an angle of $45^{\circ}$. The fixed mirror is installed inside a groove which is visible in Figure 7(b) (solid arrow).

\section{A. Calibration}

The correct alignment of the mirror angles is essential for the scanning LDV system. On the presented prototype device, these angles are set manually and small errors can have a significant influence on the measured response. A calibration process was therefore developed to ensure that the laser measurement agreed well with a reference accelerometer. In a first step, the response of a quasi-rigid target was measured at the same location with an accelerometer and the LDV to ensure 


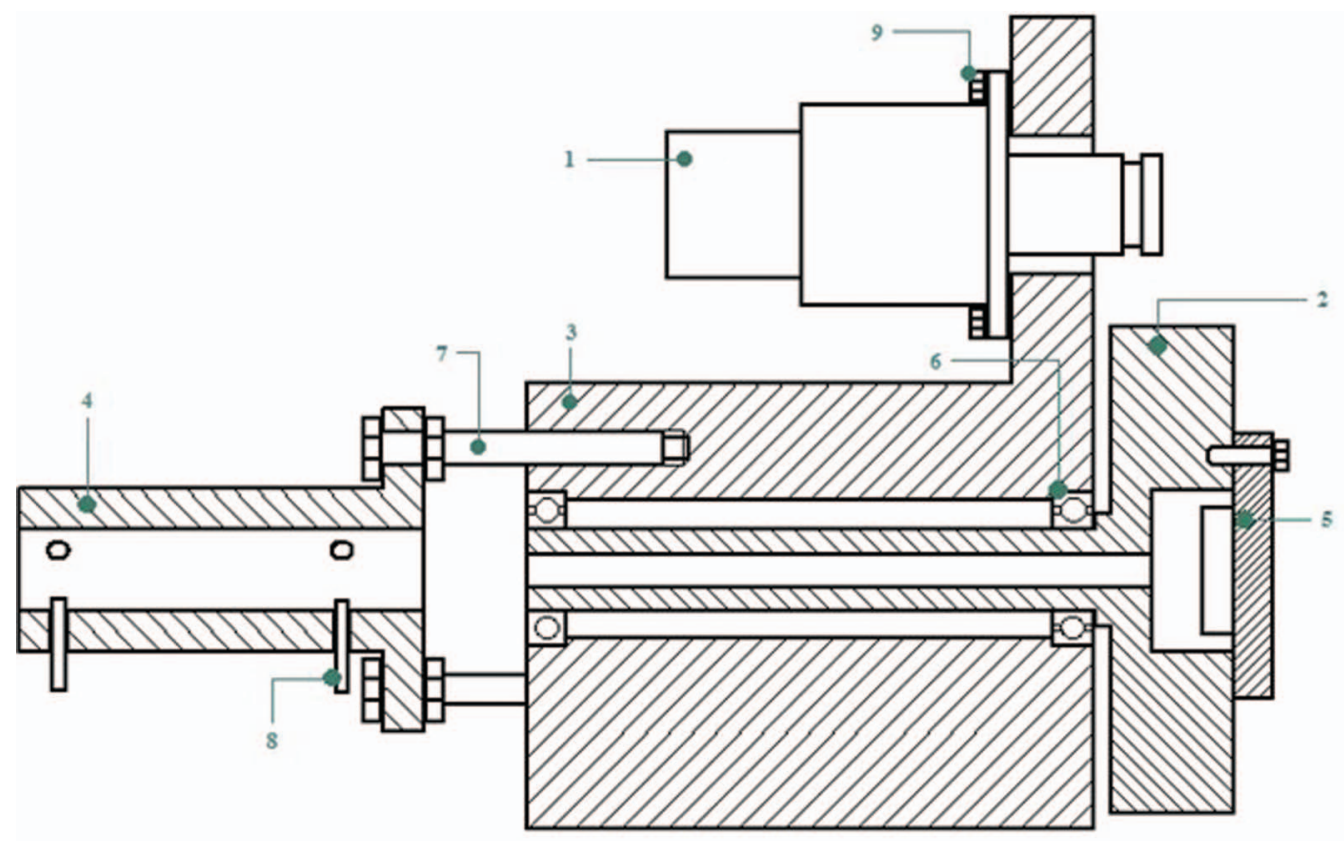

FIG. 6. Improved design of the scanning head system.
BOM

1 - Electric motor

2 - Scanning head

3 - Support

4 - Alignment system

5 - First mirror support

6 - Bearing

7 - M4 alignment screw

8 - M3 clamping screw

9 - M3 screw agreement between the velocity signal of an LDV, $V_{z L D V}$, and the integrated accelerometer signal, $V_{a c c}$. The resulting velocities showed an error of less than $0.2 \%$, which was considered adequately accurate for the intended investigation. The laser was then mounted onto the scanning device, and the scanning mirrors manually set up for a conical scan. The mirror angle was chosen to be $\varphi=20^{\circ}$ and this was checked with a goniometer. A pure out-of-plane excitation was applied to the target surface, and measured on the one hand by the reference accelerometer and on the other hand by the scanning mirror system in conical-scan configuration. Since no in-plane translation or rotation was present during the measurement, the resulting LDV signal was the unmodulated harmonic response of the excitation frequency. Repeated measurements were carried out at a frequency of $80 \mathrm{~Hz}$, and a maximum error of
$1.3 \%$ between the manually calibrated and the extracted angle $\varphi$ was detected, see Ref. 8 for further details.

A similar calibration procedure was set up for the new 6 DOF scanning device. Figure 8 shows the measurement chain. The target surface, assumed to be rigid, was secured to a horizontal low-friction guide at a $45^{\circ}$ angle. A shaker was connected to the plate with a stinger parallel to the slider guide; the connection was carefully arranged so that resulting in purely translational motion. The laser was pointed orthogonal to the surface and measured two components of motion: one in-plane in $\mathrm{X}$ direction, and the other out-of-plane, along $\mathrm{Z}$. The scanner signal was compared to those provided by two accelerometers. The component of velocity along the $\mathrm{Y}$ direction was verified to be zero magnitude. Channel 4 is referred to a potentiometer, which is used to set the trigger

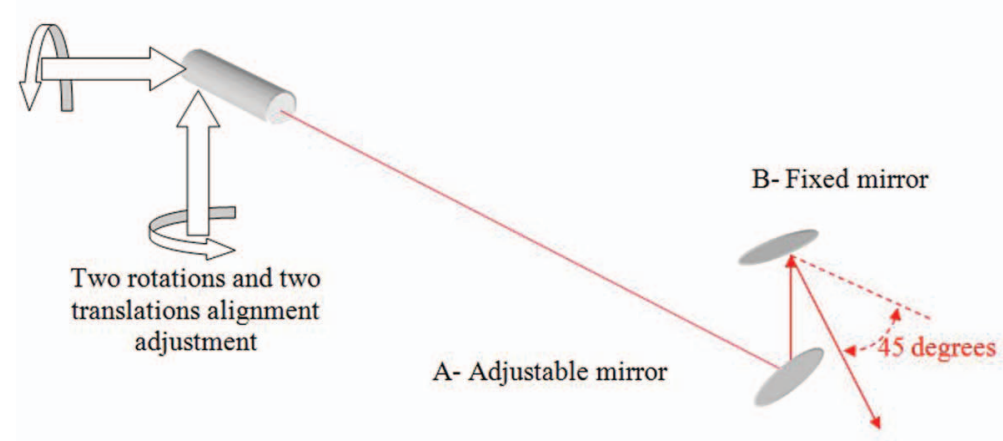

(a)

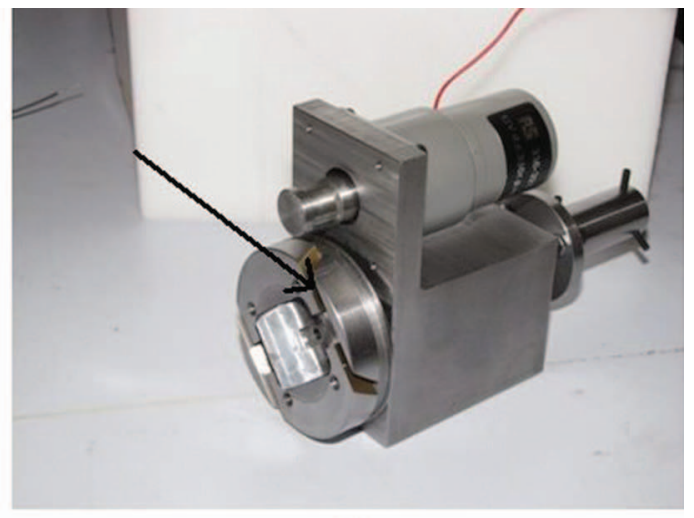

(b)

FIG. 7. Schematic of laser beam path (a) and photo of the new scanning device (b). Reprinted with permission from AIP Conf. Proc. 1457, 242 (2012). Copyright 2012 American Institute of Physics. ${ }^{10}$ 


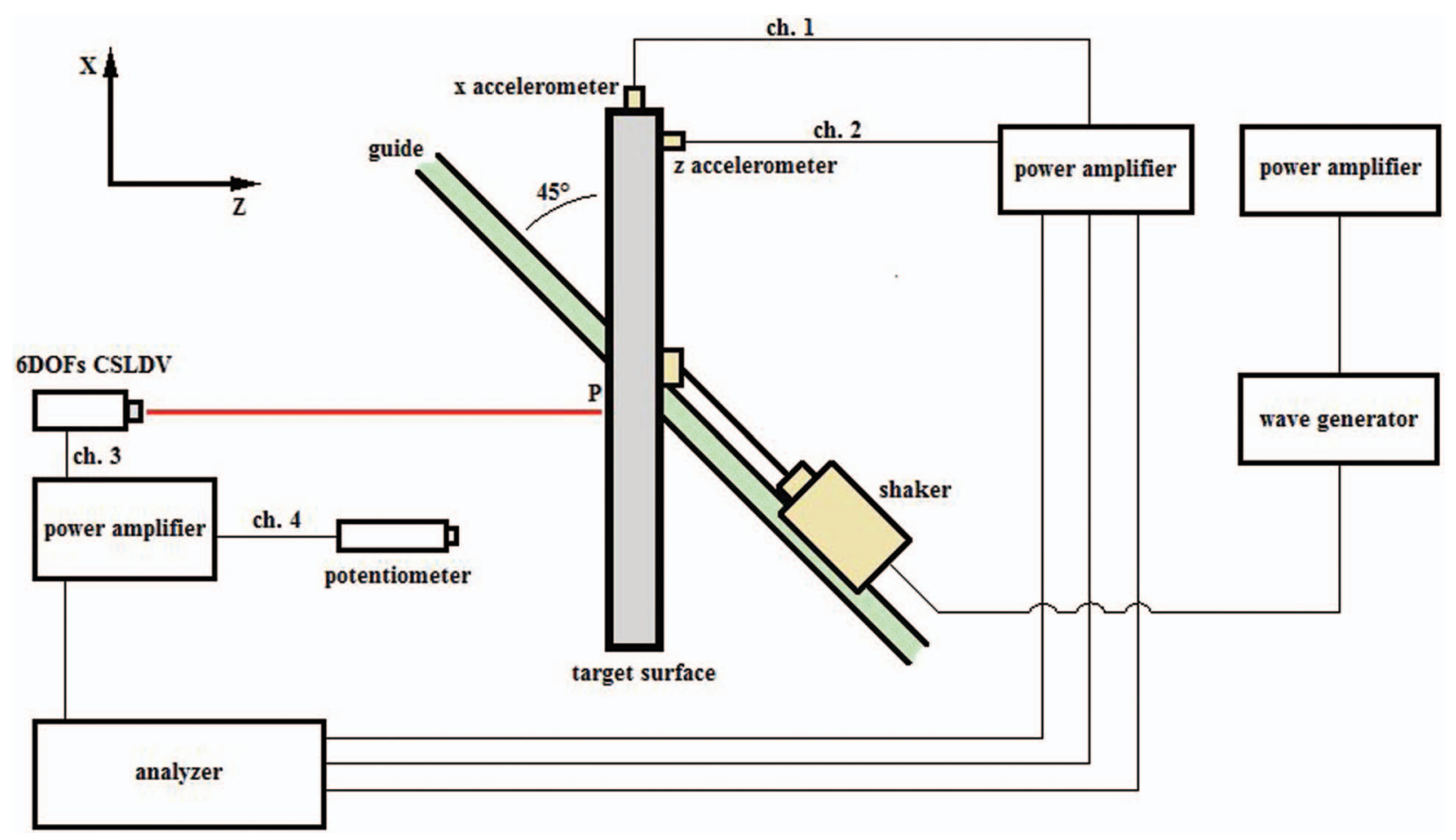

FIG. 8. Measurement set up for calibration of the new scanning device.

for all acquisition channels. The excitation sinewave from the generator was set up with six frequencies, which were $60 \mathrm{~Hz}$, $110 \mathrm{~Hz}, 160 \mathrm{~Hz}, 210 \mathrm{~Hz}, 260 \mathrm{~Hz}$, and $310 \mathrm{~Hz}$, respectively. The electric motor was powered by a voltage of $11 \mathrm{~V}$ and which produced a scanning frequency of $1 \mathrm{~Hz}$. This ensured sufficient frequency band spacing between the sidebands. The scanner vibrations were kept at an acceptably low level for the chosen scan rate. The vibration amplitudes obtained from the 6DOF scanner were compared with those provided by the accelerometers and an error smaller than $3 \%$ was calculated between the two sets of measurements.

\section{APPLICATION OF THE DOF SCANNER TO ENGINEERING TEST CASE}

Sections II and III presented and compared the design of the prototype and the new scanner. The prototype was specifically designed for targeting the in-plane rotational vibrations and therefore proving the effectiveness of the design. The achievement of this goal required that both mirrors could be adjustable so as to change the inclination of the incident laser beam to the target surface.

The new design did not need such requirements (adjustable mirrors), since each mirror requires a constant inclination in order the scanner to be able to perform of all 6 degrees of freedom measurements. However, for test case presented here the scanner was configured such that to have one fixed and one adjustable mirror. This reduced number of angular adjustments was maintained so as to help the identification of the correct angular position of $45^{\circ}$ with the target surface. This angle is identified in Ref. 8 as the angle $\beta$. The angle $\varphi$, presented in Figure 1, was set to $0^{\circ}$ because the in-plane rota- tion measurement was not required. The scanner, configured in such a way, was used for measuring the three translational vibrations so as to resolve the out of plane deflections of the specimen; the three rotational ones were not considered here.

A test structure was designed to be as similar as possible to a real engineering component and which could exhibit relevant vibrations along the three axial directions, $\mathrm{X}, \mathrm{Y}$, and $\mathrm{Z}$, respectively. For example, pipes are typically known to exhibit such vibration behaviour because of their geometry, which, in fact, can present bending along all three axial directions. Despite their simple geometry, pipes can present important challenges when both spatial and modal properties are needed to be measured along all these directions. The idea was to mimic dynamic features of these components and so a test structure was manufactured from simple squared section $(10 \times 10 \mathrm{~mm})$ beam and bent along the $\mathrm{X}, \mathrm{Y}$, and $\mathrm{Z}$ directions as shown in Figure 9. This test structure, although simple, presents vibration behaviours difficult to be measured using a single scanning LDV system.

Research work was performed in order to produce multiple comparisons between the measurements of the 6DOF scanner, those of a Polytec vibrometer, and a set of theoretical results. A list of the tasks developed is presented as follows:

- Development of a Finite Element (FE) model.

- Modal analysis of the structure with the Polytec vibrometer.

- Correlation and validation of the FE model.

- Measurements of Operational Deflection Shapes (ODSs) at the resonant frequencies using the Polytec vibrometer.

- Measurements of ODSs using the enhanced 6 DOFs scanner. 


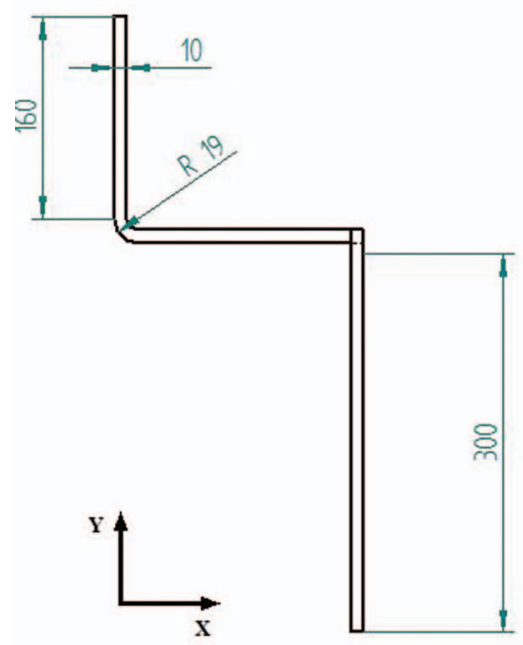

(Left)

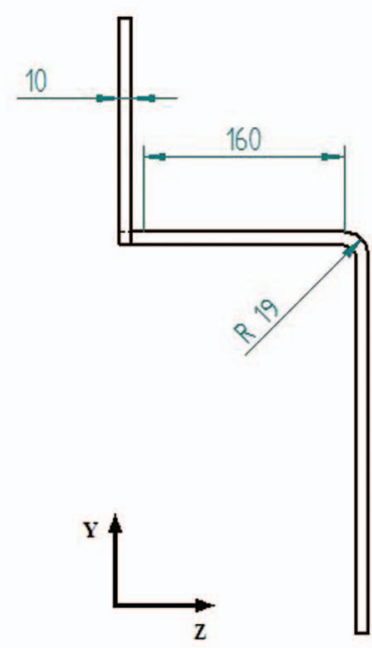

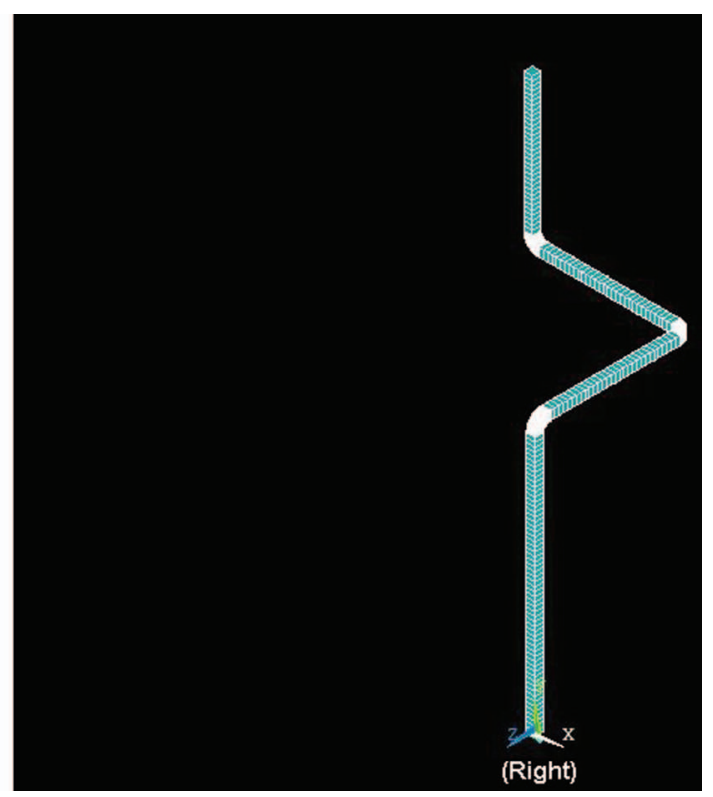

FIG. 9. Geometrical dimensions (left-hand side) and FE model (right-hand side) of the beam.

- FE simulation of ODSs.

- Comparison of results.

\section{MODAL ANALYSIS OF THE TEST STRUCTURE}

The test structure, presented in Figure 9, was manufactured with a base in order to simplify the clamping conditions. The bottom of the base had a threaded hole for installing a load cell. Modal analysis was performed in a frequency bandwidth between 80 and $300 \mathrm{~Hz}$, where the first four modes were measured. A grid of measurement points were marked on the beam as shown in Figure 10.

The test set up is presented in Figure 11. The excitation was supplied along the Y direction so that the specimen would be able to vibrate along the three directions. A load cell was installed between the shaker and the specimen. A Polytec PSV-300 Scanning LDV system was used for measuring the responses at the measurement points. It is clear at this stage that a single measurement would not be sufficient for resolving the vibrations along $\mathrm{X}, \mathrm{Y}$, and $\mathrm{Z}$ directions. Hence, three measurements were performed by aligning the SLDV along one of the axial directions and this practice increased the testing time quite considerably.

Modal analysis was performed using ICATS software, ${ }^{9}$ four mode shapes were measured in the frequency bandwidth chosen and the natural frequencies are listed in Table I.

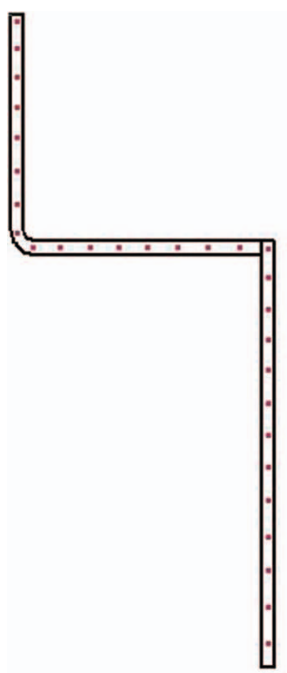

$\mathrm{XY}$ scanning

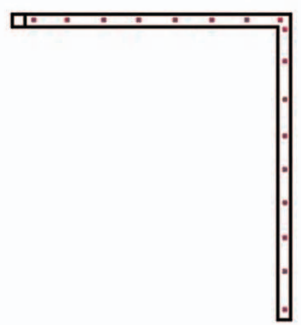

XZ scanning

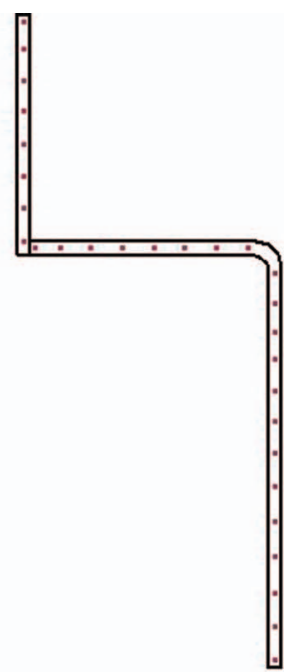

YZ scanning

FIG. 10. Grid of measurement points marked on the beam along the three directions. 


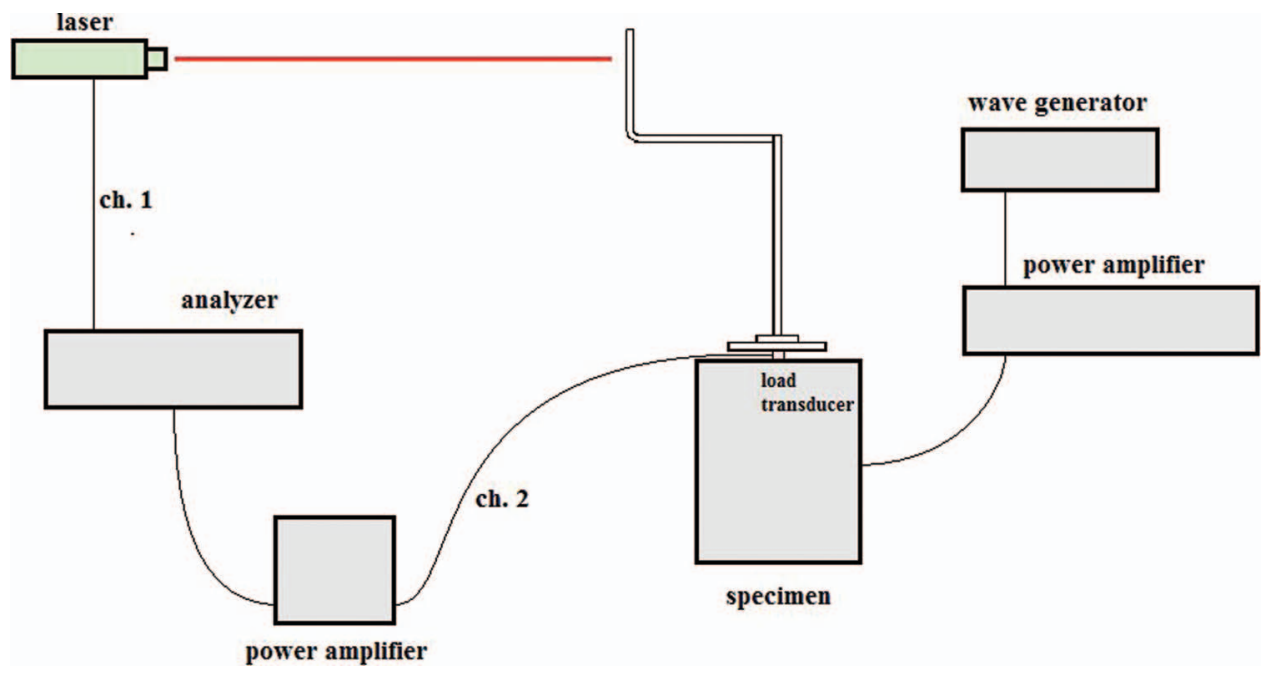

FIG. 11. Test configuration.

One mode shape at $91.3 \mathrm{~Hz}$ is presented here, see Figure 12. The other three mode shapes are presented in Appendix A of this paper.

\section{FE MODELLING AND MAC CORRELATION}

A rapid validation of the FE model was required although the very simple test structure was under study. However, the base was manufactured but not modelled in the FE analysis and therefore that had to be included in the validation. The base was modelled by having translations in the $\mathrm{X}$ and $\mathrm{Z}$ directions, and rotation along $\mathrm{Y}$ was fully constrained. Then, an inertial element was inserted at the base of the beam so as to simulate the real one manufactured, as shown in Figure 13.

By setting the real constants to the values indicated (MASS $\mathrm{X}=, \mathrm{Y}=, \mathrm{Z}=0.222 \mathrm{~kg})$ and $\left(\mathrm{I}_{\mathrm{XX}}=, \mathrm{I}_{\mathrm{YY}}=, \mathrm{I}_{\mathrm{ZZ}}\right.$ $=0.3668 \times 10^{-3} \mathrm{~kg} \mathrm{~m}^{2}$ ) is possible to model the real impedance of the bond in the remaining degrees of freedom and so without having those completely blocked. The mass and stiffness properties of the system were subsequently adjusted. The specific weight of the bar was set at $7860 \mathrm{~kg} \mathrm{~m}^{-3}$, so that the mass was equivalent to the real specimen. Young modulus was then set at $220 \mathrm{GPa}$, a value that minimizes the deviation between real and simulated modal frequencies. This value has been found running different simulations, varying stiffness, and using Excel program to calculate the deviation. The FE analysis produced 8 mode shapes in a frequency bandwidth between 10 and $500 \mathrm{~Hz}$, and Table II presents the natural frequencies.

Maximum Assurance Criterion (MAC) was used for correlating the experimental with the theoretical modes, and Tables III-V present the correlation values.

\section{MEASUREMENT AND CORRELATION OF ODSS USING 6DOF AND POLYTEC SLDV SYSTEMS}

Having measured and calculated the mode shapes of the specimen, the next step was to perform measurements of the
ODSs using both the SLDV Polytec system and the 6DOF scanner presented here. This section is dived in two parts: (i) first one presenting the ODSs measured by the two systems and simulated using FE analysis code and (ii) in the second part MAC correlations are performed between measurements and simulations.

\section{A. Simulation and measurement of the ODSs}

Simulation was carried out by conducting harmonic analysis of the FE model presented in Sec. IV. The excitation force was set at $50 \mathrm{~N}$ along the $\mathrm{Y}$ direction and at the base of the specimen. Boundary conditions were unchanged: translations were still blocked in $\mathrm{X}$ and $\mathrm{Z}$ directions, as was rotation along Y. Four excitation frequencies, as presented in Table VI, were used for calculating and measuring the ODSs of the test structure.

The measurement of the ODSs was carried out using a Polytec PSV-300 system. Hence, three sets of measurements were needed so as to get the ODSs along the three directions, $\mathrm{X}, \mathrm{Y}$, and Z, respectively. Figure 14 shows the simulated (top) and measured (bottom) ODS at $91 \mathrm{~Hz}$. It is possible to find the other ODSs in Appendix B.

The last set of measurements was carried out using the presented 6DOF scanning device. The measurement points are presented in Figure 15 and are the same of the ones used for the SLDV measurements but of reduced number. The 6DOF scanner installed an adjustable ball screw vertical slider, the horizontal position required the movement of that installation. It must be said that the arrangement worked well for this proof of concept application but it was quite unpractical. An ideal system would be to have the 6DOF scanner installed on a robot arm, which could address measurement points automatically. Figure 16 shows the test configuration and Figure 17 screen shots of one measurement point for ODS at $131 \mathrm{~Hz}$.

Four ODSs were measured and two of those are presented here in Figure 18. ODSs measured at 91 and $130 \mathrm{~Hz}$ are 


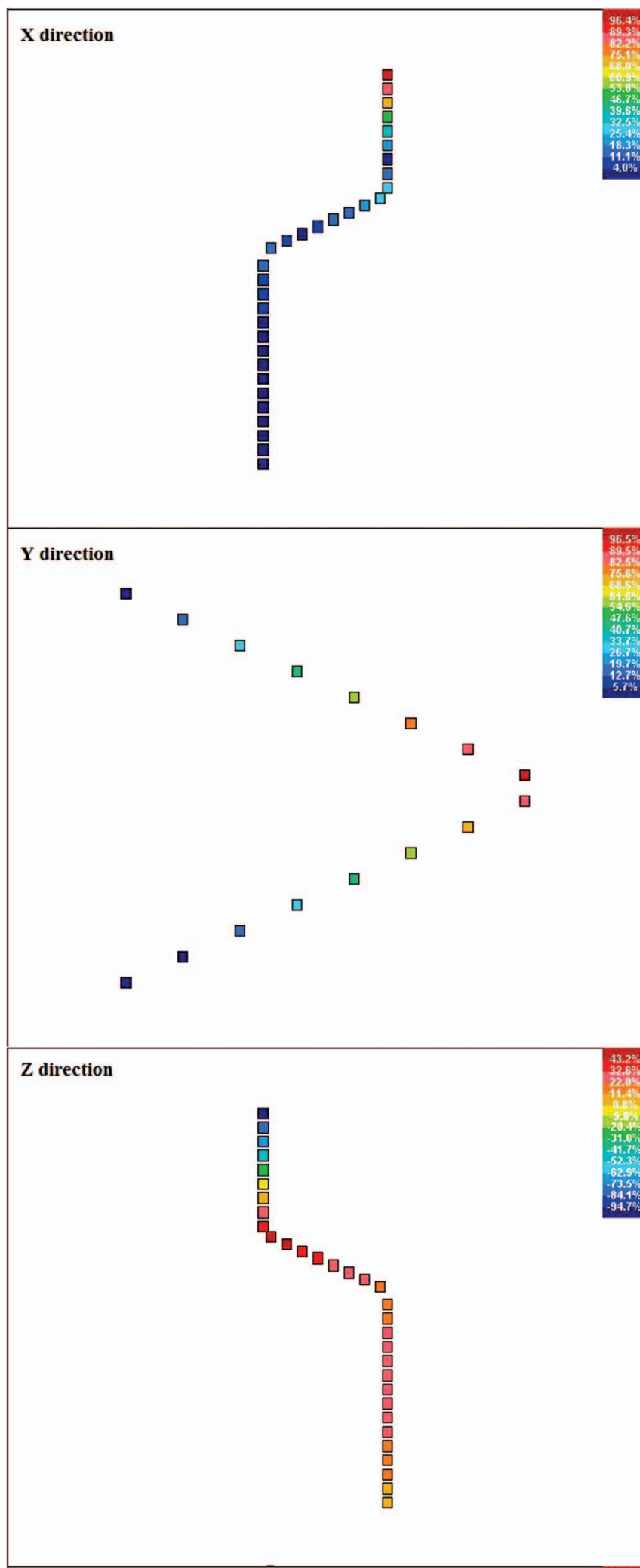

FIG. 12. Mode shape at $91.3 \mathrm{~Hz}$ along $\mathrm{X}, \mathrm{Y}$, and $\mathrm{Z}$ directions.

available in Appendix $\mathrm{C}$ because of the poor quality of the figure, which unfortunately could not be improved because the original data were unrecoverable after the production of this paper.
TABLE I. Natural frequencies of the test structure.

\begin{tabular}{lcccc}
\hline \hline & Mode 1 & Mode 2 & Mode 3 & Mode 4 \\
\hline Freq. & $91.3 \mathrm{~Hz}$ & $131.1 \mathrm{~Hz}$ & $209.4 \mathrm{~Hz}$ & $292.8 \mathrm{~Hz}$ \\
Damp. & 2.5 & 1.3 & 1.1 & 0.9 \\
\hline \hline
\end{tabular}

\section{B. MAC correlation between simulated and measured ODSs}

ODSs were correlated so as to provide an exhaustive analysis of the three sets of results. The Y direction components of the two ODSs, for frequencies at 209 and 293, were however excluded because their vibration magnitudes were negligible compared with those of the other ODSs. All MAC correlations were performed between the ODSs measured by the Polytec vibrometer and those provided by FE analysis.

Table VII shows the correlations in $\mathrm{X}, \mathrm{Y}$, and $\mathrm{Z}$ between FE analysis and experimental data captured using Polytec SLDV system.

Table VIII shows the correlation between 6DOF scanner and Polytec SLDV system, and Table IX shows the one between 6DOF scanner and FE analysis. It is possible to say that the 6DOF scanner is capable of performing good quality measurements along the three axial directions by a single set of acquisitions.

\section{DISCUSSIONS}

The 6DOF scanning device, presented here, has got a rather more compact design than its predecessor and, in fact, the size of the full assembly can be hold inside one hand. Clearly, this has made the system more flexible for performing measurements. The new alignment system has simplified very much the set up of the fibre optic laser probe and its alignment. It was introduced earlier that the angle by which it is possible to measure the in-plane rotational vibrations was suppressed. However, that feature can be easily implemented in the new system. The heavier scanning head increased the inertia of the shaft and thus helped to stabilize the rotational speed. This is an important parameter, which determines the distance between the two sidebands and therefore is critical to have that constant during the acquisition time. The signal-tonoise ratio (SNR) was not always good because of the LDV fibre optic, which has got a fixed working distance for a good quality SNR. This requirement was known it was decided to continue using the fibre optic because being that very manageable. The alternative solution would have been replacing the fibre optic probe with an LDV single point but that would have made the full assembly more voluminous. If this latter solution is to be the choice then the assembly would be better mounted on a robot arm, which can allow automatic positioning of the measurement system.

The new measurement system proved to be able to measure with accuracy the four ODSs selected for this experimental validation. It was clear that a single SLDV system requires too much setting up for performing this type of 


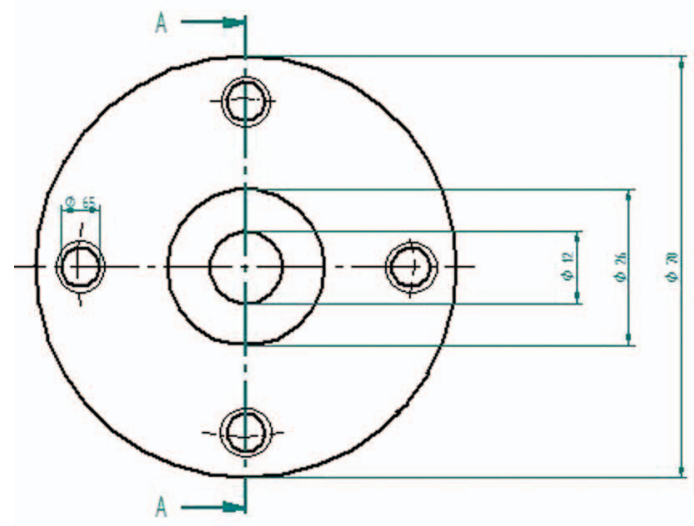

(a)

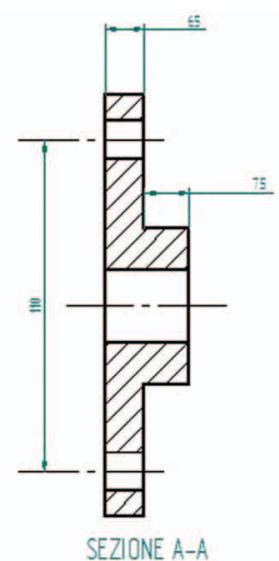

SEZIONE A-A

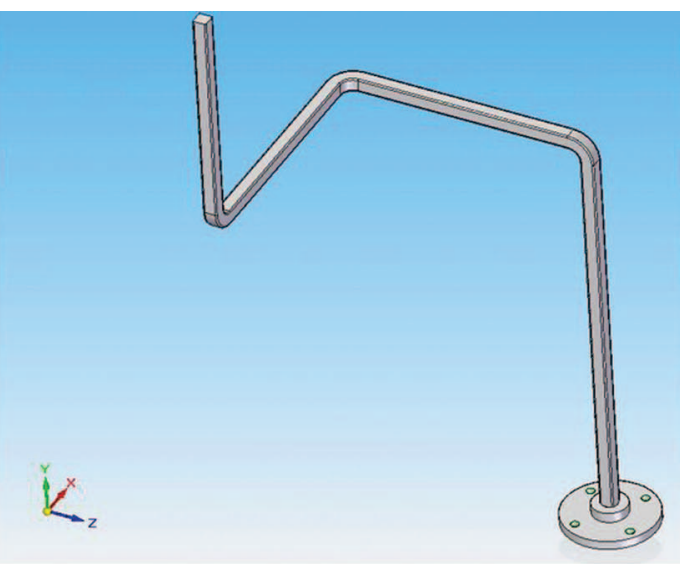

(b)

FIG. 13. Geometrical dimension of the base (a) and full solid model (b).

TABLE II. Natural frequencies calculated from FE analysis.

\begin{tabular}{ccccccccc}
\hline \hline Mode & 1 & 2 & 3 & 4 & 5 & 6 & 7 & 8 \\
\hline Freq. & $38.9 \mathrm{~Hz}$ & $46.7 \mathrm{~Hz}$ & $91.2 \mathrm{~Hz}$ & $130.4 \mathrm{~Hz}$ & $209.3 \mathrm{~Hz}$ & $253.4 \mathrm{~Hz}$ & $319.5 \mathrm{~Hz}$ & $350.4 \mathrm{~Hz}$ \\
\hline \hline
\end{tabular}

TABLE III. MAC along $\mathrm{X}$ direction.

\begin{tabular}{|c|c|c|c|c|c|c|c|c|}
\hline MAC X & 1 FEM & 2 FEM & 3 FEM & 4 FEM & 5 FEM & 6 FEM & 7 FEM & 8 FEM \\
\hline 1 Exper. & & & 0.93 & & & & & \\
\hline 2 Exper. & & & & 0.98 & & & & \\
\hline 3 Exper. & & & & & 0.98 & & & \\
\hline 4 Exper. & & & & & & & 0.96 & \\
\hline
\end{tabular}

TABLE IV. MAC along Y direction.

\begin{tabular}{|c|c|c|c|c|c|c|c|c|}
\hline MAC Y & 1 FEM & 2 FEM & 3 FEM & 4 FEM & 5 FEM & 6 FEM & 7 FEM & 8 FEM \\
\hline 1 Exper. & & & 1.00 & & & & & \\
\hline 2 Exper. & & & & 0.97 & & & & \\
\hline 3 Exper. & & & & & 0.83 & & & \\
\hline 4 Exper. & & & & & & & 0.73 & \\
\hline
\end{tabular}

TABLE V. MAC along $\mathrm{Z}$ direction.

\begin{tabular}{|c|c|c|c|c|c|c|c|c|}
\hline MAC Z & 1 FEM & 2 FEM & 3 FEM & 4 FEM & 5 FEM & 6 FEM & 7 FEM & 8 FEM \\
\hline 1 Exper. & & & 0.98 & & & & & \\
\hline 2 Exper. & & & & 0.96 & & & & \\
\hline 3 Exper. & & & & & 0.99 & & & \\
\hline 4 Exper. & & & & & & & 0.97 & \\
\hline
\end{tabular}


TABLE VI. Excitation frequencies used for measuring the ODSs of the specimen.

\begin{tabular}{lc}
\hline \hline & Freq. \\
\hline ODS 1 & $91 \mathrm{~Hz}$ \\
ODS 2 & $131 \mathrm{~Hz}$ \\
ODS 3 & $209 \mathrm{~Hz}$ \\
ODS 4 & $293 \mathrm{~Hz}$ \\
\hline \hline
\end{tabular}

Simulated ODS AT $91 \mathrm{~Hz}$

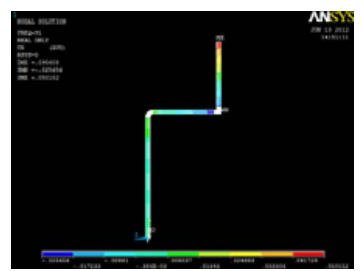

$\mathrm{X}$ direction

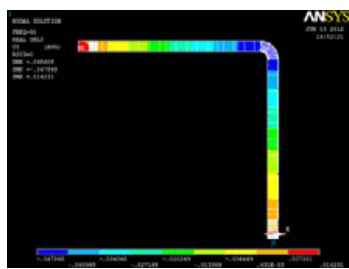

Y direction

Measured ODS at $91 \mathrm{~Hz}$
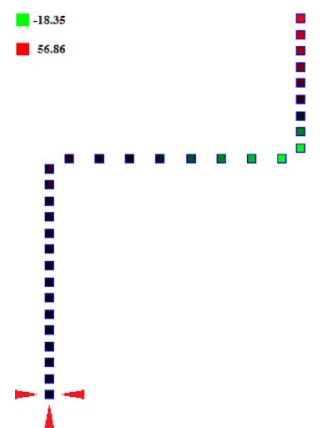

$\mathrm{X}$ direction

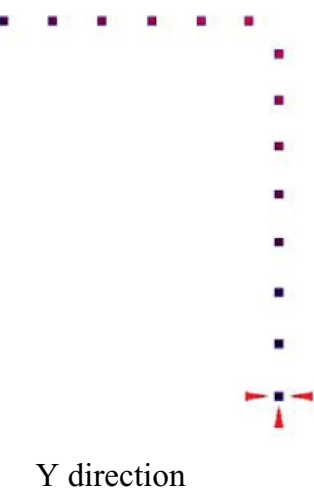

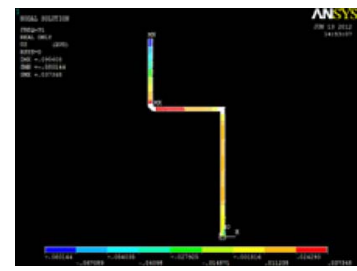

$Z$ direction

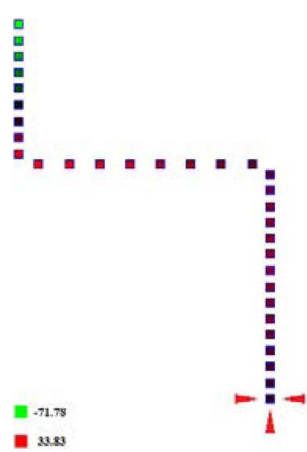

$\mathrm{Z}$ direction

FIG. 14. Simulation and measurement of ODSs.
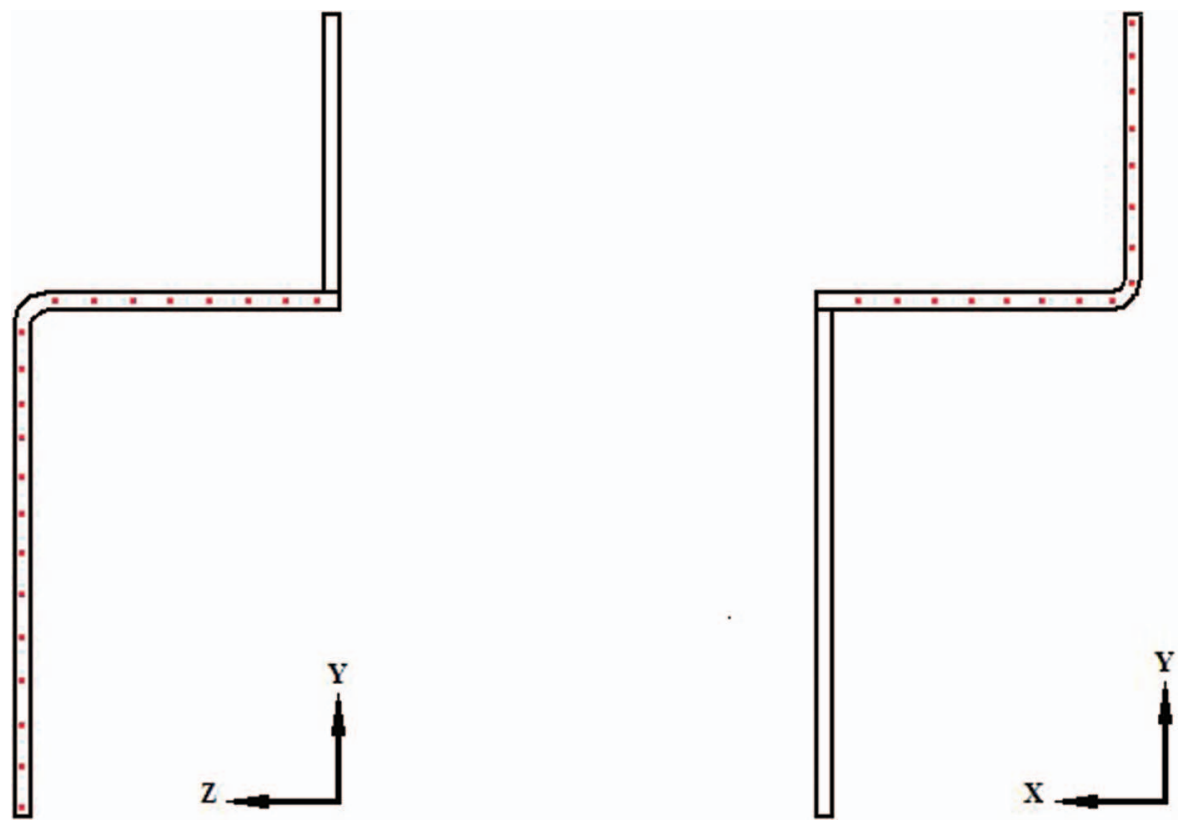

FIG. 15. Measurement points 


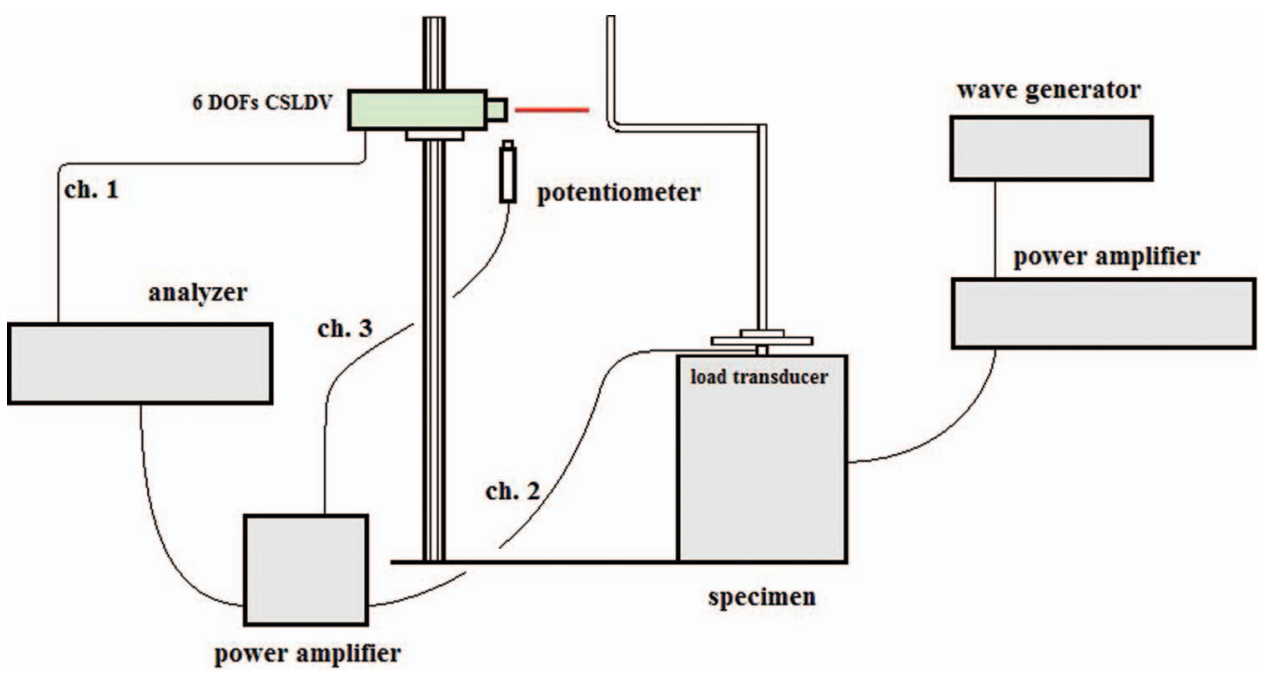

FIG. 16. Test configuration.

measurements. However, this can be overcome by using a 3D SLDV system and which is commercially available. The major advantage of the proposed scanner is the simplicity of the design which enables a single point and, relatively cheap, LDV to measure up to 6 degrees of freedom at a target. Hence, continuous scanning LDV methods are powerful measurement techniques exploited very well by using of the new hardware.
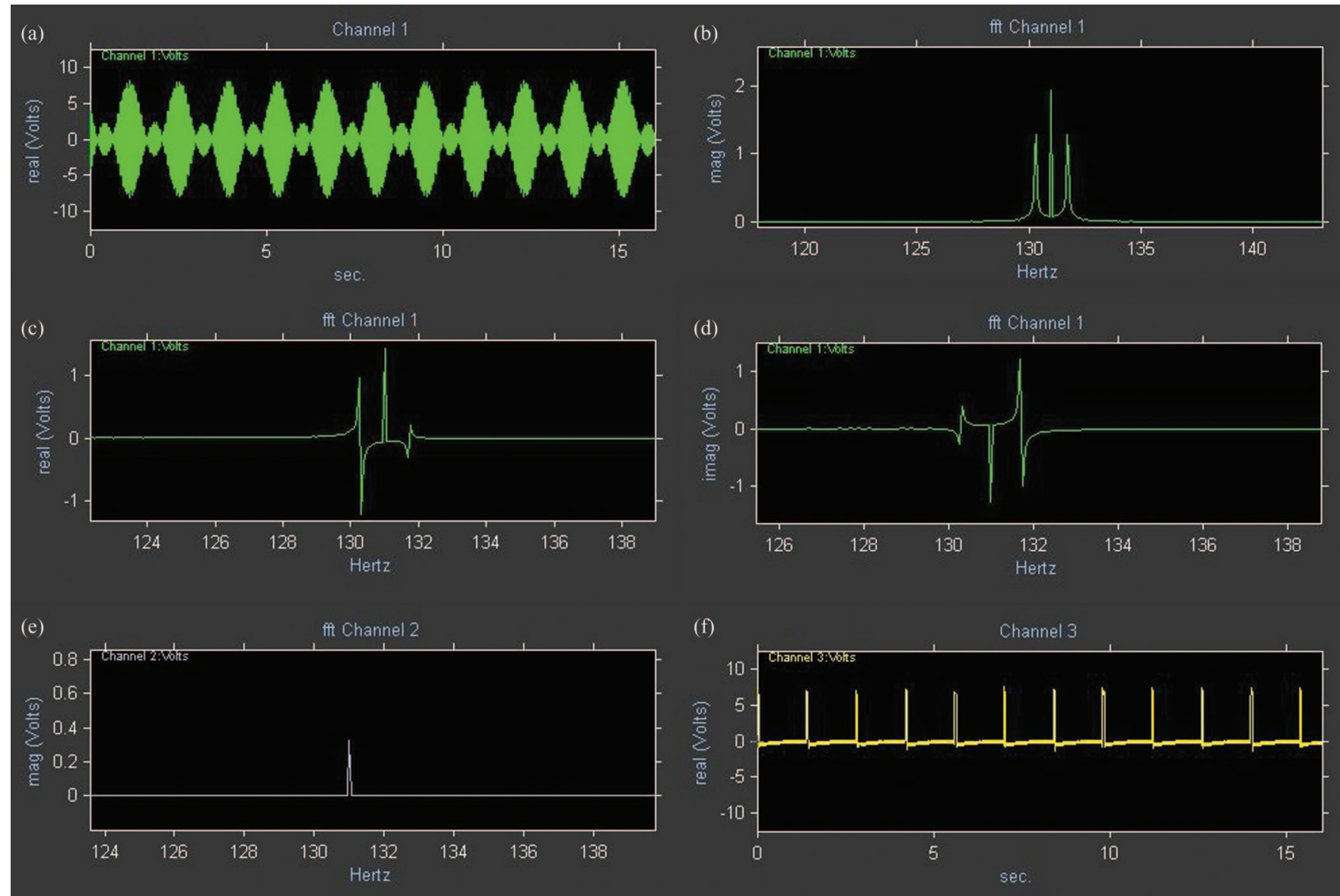

FIG. 17. Screen shots of acquisition channels. (a) LDV output signal. (b) Magnitude of LDV spectrum. (c) Real part of LDV output signal. (d) Imaginary part of LDV output signal. (e) Excitation frequency. (f) Signal from the potentiometer. 
ODS AT $209 \mathrm{~Hz}$
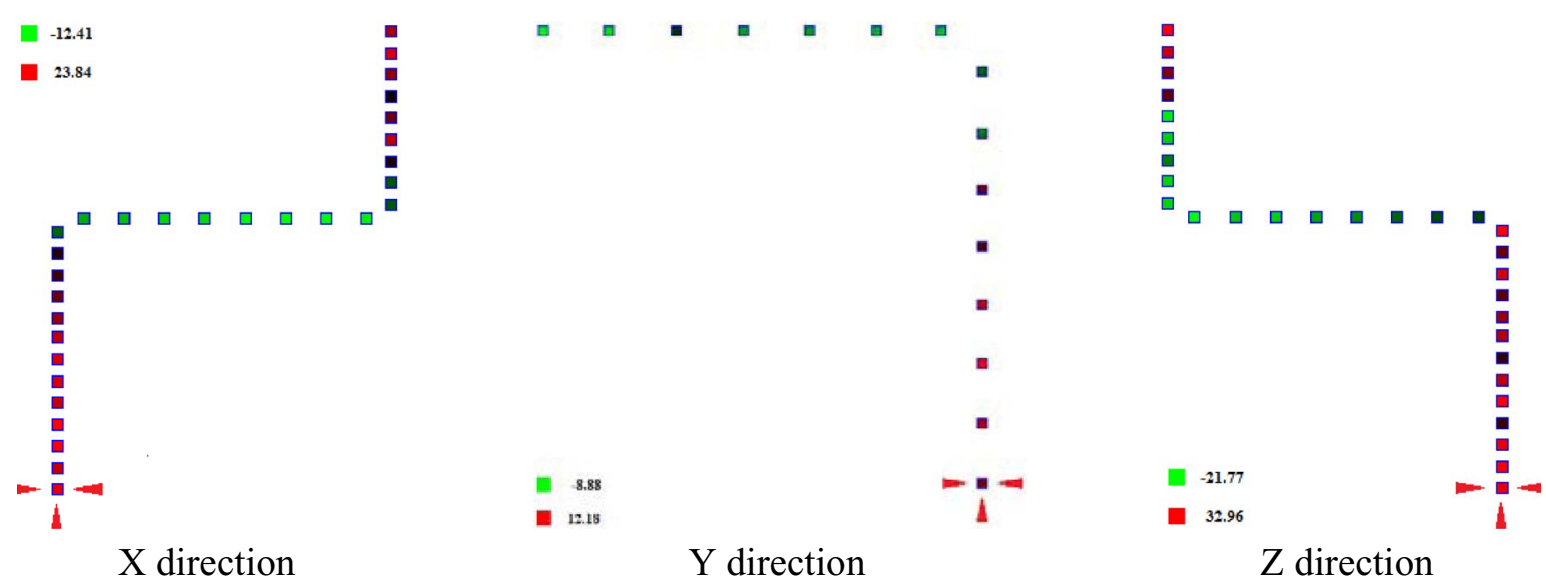

ODS AT $293 \mathrm{~Hz}$

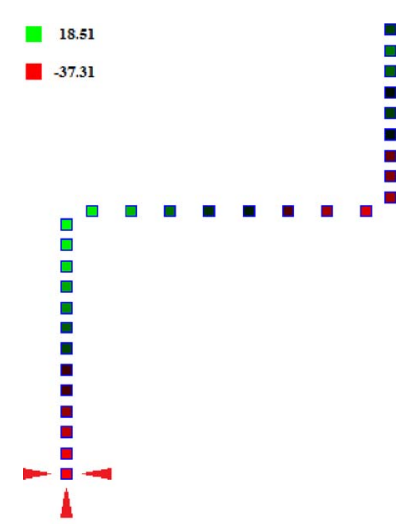

$\mathrm{X}$ direction

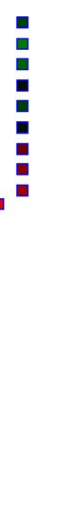

- 13.91

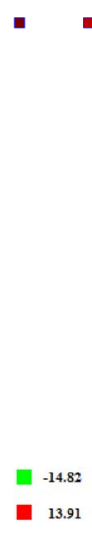

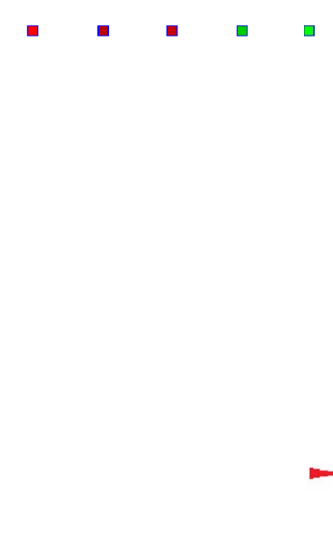

Y direction

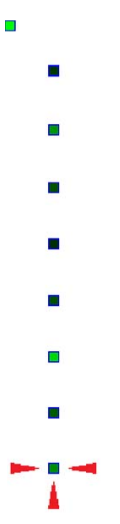

$-$

FIG. 18. ODSs measurement data.

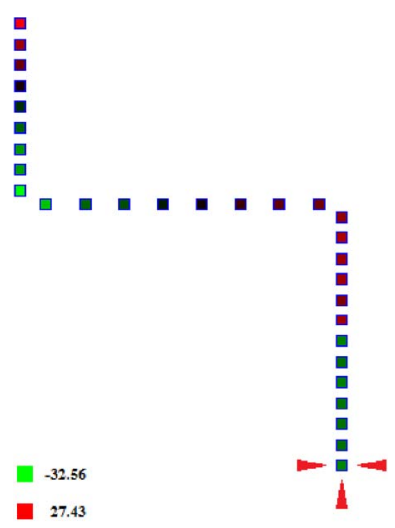

$\mathrm{Z}$ direction

TABLE VII. MAC between FE analysis and Polytec SLDV system.

\begin{tabular}{|c|c|c|c|c|}
\hline MAC X & FE ODS $91 \mathrm{~Hz}$ & FE ODS $130 \mathrm{~Hz}$ & FE ODS $209 \mathrm{~Hz}$ & FE ODS $320 \mathrm{~Hz}$ \\
\hline Polytec ODS $91 \mathrm{~Hz}$ & 0.98 & & & \\
\hline Polytec ODS $130 \mathrm{~Hz}$ & & 0.99 & & \\
\hline Polytec ODS $209 \mathrm{~Hz}$ & & & 0.98 & \\
\hline Polytec ODS $293 \mathrm{~Hz}$ & & & & 0.96 \\
\hline MAC Z & FE ODS $91 \mathrm{~Hz}$ & FE ODS $130 \mathrm{~Hz}$ & FE ODS $209 \mathrm{~Hz}$ & FE ODS $320 \mathrm{~Hz}$ \\
\hline Polytec ODS $91 \mathrm{~Hz}$ & 0.98 & & & \\
\hline Polytec ODS $130 \mathrm{~Hz}$ & & 0.99 & & \\
\hline Polytec ODS $209 \mathrm{~Hz}$ & & & 0.97 & \\
\hline Polytec ODS $293 \mathrm{~Hz}$ & & & & 0.97 \\
\hline MAC Y & \multirow{2}{*}{\multicolumn{2}{|c|}{$\begin{array}{c}\text { FE ODS } 91 \mathrm{~Hz} \\
1.00\end{array}$}} & \multicolumn{2}{|c|}{ FE ODS $130 \mathrm{~Hz}$} \\
\hline Polytec ODS $91 \mathrm{~Hz}$ & & & & \\
\hline Polytec ODS $130 \mathrm{~Hz}$ & & & \multicolumn{2}{|c|}{0.97} \\
\hline
\end{tabular}


TABLE VIII. MAC between Polytec SLDV system and 6DOF scanner.

\begin{tabular}{|c|c|c|c|c|}
\hline MAC X & $\begin{array}{l}\text { 6DOF scanner } \\
\text { ODS } 91 \mathrm{~Hz}\end{array}$ & $\begin{array}{l}\text { 6DOF scanner } \\
\text { ODS } 130 \mathrm{~Hz}\end{array}$ & $\begin{array}{l}\text { 6DOF scanner } \\
\text { ODS } 209 \mathrm{~Hz}\end{array}$ & $\begin{array}{c}\text { 6DOF scanner } \\
\text { ODS } 293 \mathrm{~Hz}\end{array}$ \\
\hline Polytec ODS $91 \mathrm{~Hz}$ & 0.79 & & \multirow{4}{*}{0.90} & \multirow[b]{4}{*}{0.96} \\
\hline Polytec ODS $130 \mathrm{~Hz}$ & & 0.95 & & \\
\hline Polytec ODS $209 \mathrm{~Hz}$ & & & & \\
\hline Polytec ODS $293 \mathrm{~Hz}$ & & & & \\
\hline MAC Z & $\begin{array}{l}\text { 6DOF scanner } \\
\text { ODS } 91 \mathrm{~Hz}\end{array}$ & $\begin{array}{l}\text { 6DOF scanner } \\
\text { ODS } 130 \mathrm{~Hz}\end{array}$ & $\begin{array}{l}\text { 6DOF scanner } \\
\text { ODS } 209 \mathrm{~Hz}\end{array}$ & $\begin{array}{c}\text { 6DOF scanner } \\
\text { ODS } 293 \mathrm{~Hz}\end{array}$ \\
\hline Polytec ODS $91 \mathrm{~Hz}$ & 0.88 & & & \\
\hline Polytec ODS $130 \mathrm{~Hz}$ & & 0.96 & & \\
\hline Polytec ODS $209 \mathrm{~Hz}$ & & & 0.80 & \\
\hline Polytec ODS $293 \mathrm{~Hz}$ & & & & 0.88 \\
\hline MAC Y & \multicolumn{2}{|c|}{ 6DOF scanner ODS $91 \mathrm{~Hz}$} & \multicolumn{2}{|c|}{ 6DOF scanner ODS $130 \mathrm{~Hz}$} \\
\hline Polytec ODS $91 \mathrm{~Hz}$ & \multicolumn{2}{|c|}{0.88} & & \\
\hline Polytec ODS $130 \mathrm{~Hz}$ & & & \multicolumn{2}{|c|}{0.65} \\
\hline
\end{tabular}

\section{CONCLUSIONS}

This paper presented a research work aimed to validate out of plane deflection shapes of a specimen, bending along the 3 axial directions, which were measured using a new concept of scanning device. The approached presented in this paper shows that a single LDV can be used for measuring more than a single degree of freedom. This is possible because of the continuous scanning measurement method, which allows to sense the vibrations continuously along the laser beam trajectory. This means that a laser beam needs to be moved continuously and that was achieved by designing a prototype of scanning device. That was specifically produced for proving the ability of measuring in-plane rotations. Therefore, the system design allowed several mirrors' angular configurations but these features made the scanner very impractical for real engineering applications. The new design was thought to be more compact and manageable than the earlier one. The dual mirrors system was manufactured compact and keeping a limited number of angular configurations so as to focus on the translational rather than the rotational vibrations. The experimental validation of the out of plane deflection shapes was achieved by designing a beam (square section) bent along the three axial directions and excited along one of those. The test structure exhibited vibrations along $\mathrm{X}, \mathrm{Y}$, and $\mathrm{Z}$ directions and so four ODSs were measured using both the new 6DOF and an SLDV systems. An FE analysis of the test structure was also carried out and MAC correlations between the two experimental systems and the FE predictions were yielded. These correlations were good and therefore proving the effectiveness of the new $6 \mathrm{DOF}$ scanner design. Hence, the new scanning device can be used for measuring translational, as demonstrated in this paper, and rotational degrees of freedom depending on the measurement method applied and angular configuration of the mirrors.

\section{ACKNOWLEDGMENTS}

The authors wish to thank the late A. B. Stanbridge for his original idea and also Clive Rendall for supporting the latest scanning head design.

TABLE IX. MAC between FE analysis and 6DOF scanner.

\begin{tabular}{|c|c|c|c|c|}
\hline MAC X & FE ODS $91 \mathrm{~Hz}$ & FE ODS $130 \mathrm{~Hz}$ & FE ODS $209 \mathrm{~Hz}$ & FE ODS $320 \mathrm{~Hz}$ \\
\hline 6DOF scanner ODS $91 \mathrm{~Hz}$ & \multirow[t]{4}{*}{0.81} & & \multirow{4}{*}{0.89} & \multirow[b]{4}{*}{0.94} \\
\hline 6DOF scanner ODS $130 \mathrm{~Hz}$ & & 0.93 & & \\
\hline 6DOF scanner ODS $209 \mathrm{~Hz}$ & & & & \\
\hline 6DOF scanner ODS $293 \mathrm{~Hz}$ & & & & \\
\hline MAC Z & FE ODS $91 \mathrm{~Hz}$ & FE ODS $130 \mathrm{~Hz}$ & FE ODS $209 \mathrm{~Hz}$ & FE ODS $320 \mathrm{~Hz}$ \\
\hline 6DOF scanner ODS $91 \mathrm{~Hz}$ & 0.89 & & & \\
\hline 6DOF scanner ODS $130 \mathrm{~Hz}$ & & 0.95 & & \\
\hline 6DOF scanner ODS $209 \mathrm{~Hz}$ & & & \multirow[t]{2}{*}{0.81} & \\
\hline 6DOF scanner ODS $293 \mathrm{~Hz}$ & & & & 0.86 \\
\hline MAC Y & \multirow{3}{*}{\multicolumn{2}{|c|}{$\begin{array}{c}\text { FE ODS } 91 \mathrm{~Hz} \\
0.88\end{array}$}} & \multirow{2}{*}{\multicolumn{2}{|c|}{ FE ODS $130 \mathrm{~Hz}$}} \\
\hline 6DOF scanner ODS $91 \mathrm{~Hz}$ & & & & \\
\hline 6DOF scanner ODS $130 \mathrm{~Hz}$ & & & \multicolumn{2}{|c|}{0.66} \\
\hline
\end{tabular}


APPENDIX A: THREE ADDITIONAL MODE SHAPES IDENTIFIED FROM THE TEST STRUCTURE

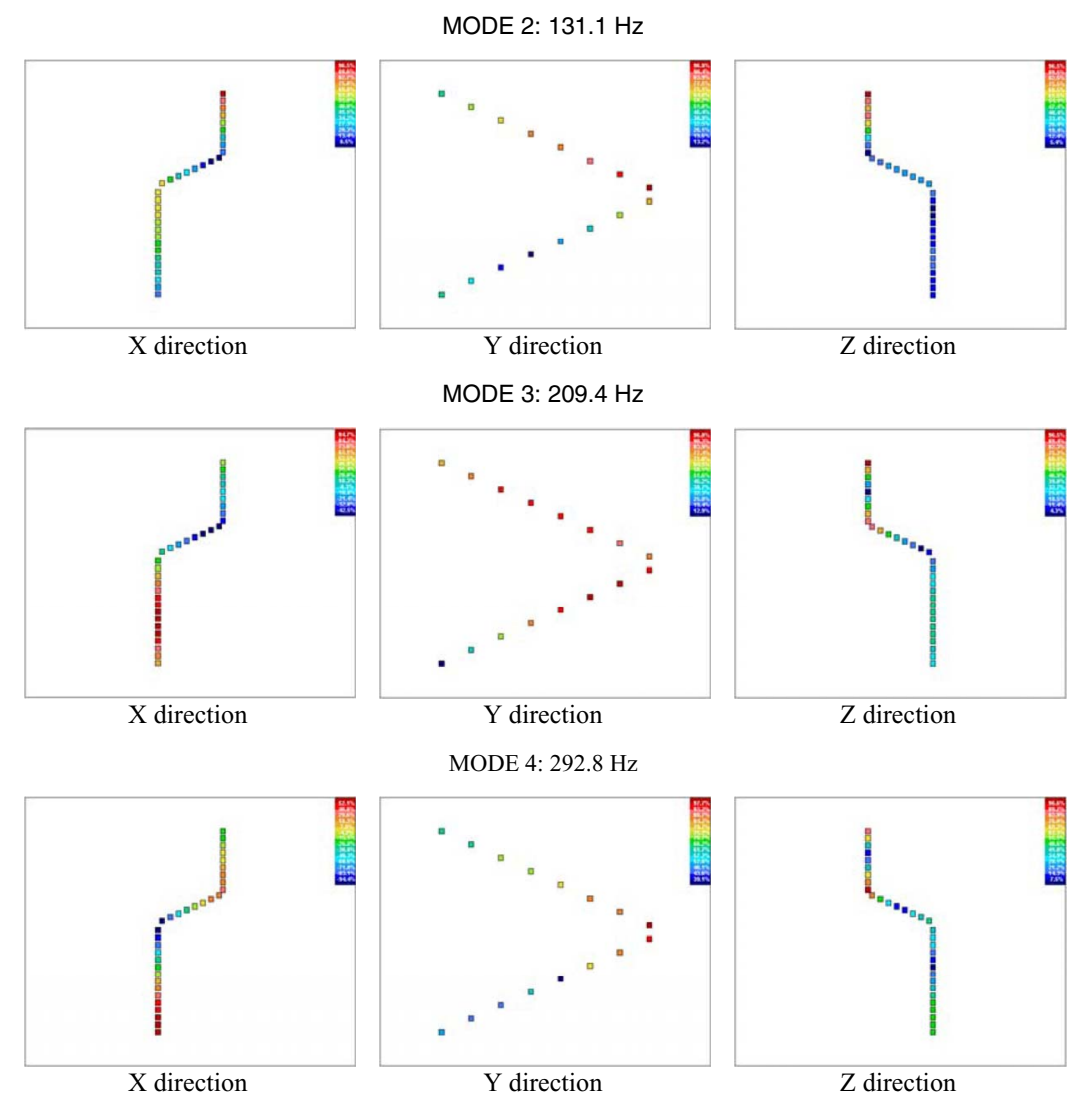

APPENDIX B: ODSs SIMULATED WITH FE CODE (FIRST 9 FIGURES) AND MEASURED USING POLYTEC SLDV SYSTEM (REMAINING 9 FIGURES)

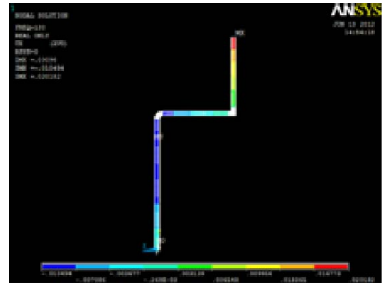

$\mathrm{X}$ direction

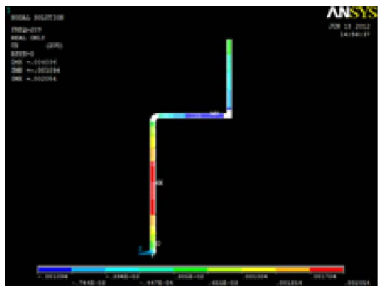

$\mathrm{X}$ direction

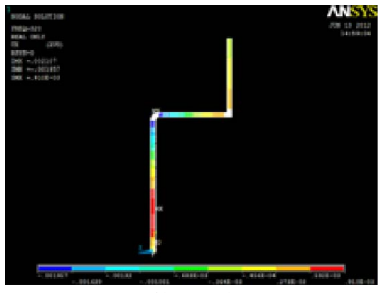

$\mathrm{X}$ direction

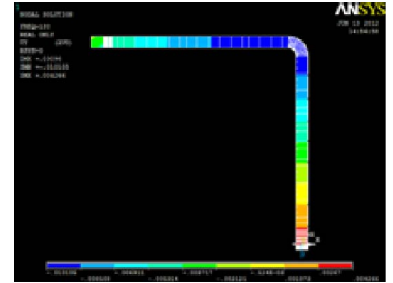

Y direction

ODS AT $209 \mathrm{~Hz}$

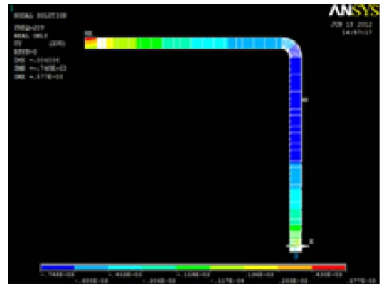

Y direction

ODS AT $320 \mathrm{~Hz}$

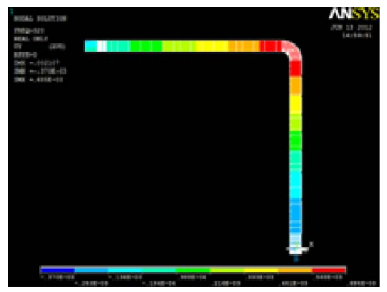

Y direction

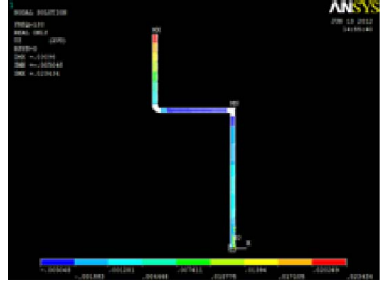

$\mathrm{Z}$ direction

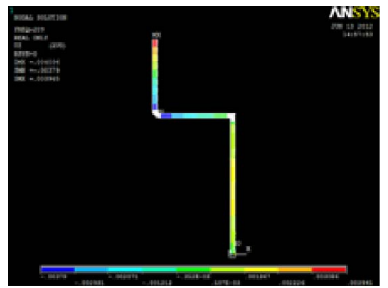

$\mathrm{Z}$ direction

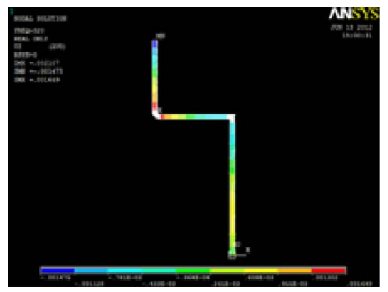

$\mathrm{Z}$ direction 
ODS AT $130 \mathrm{~Hz}$

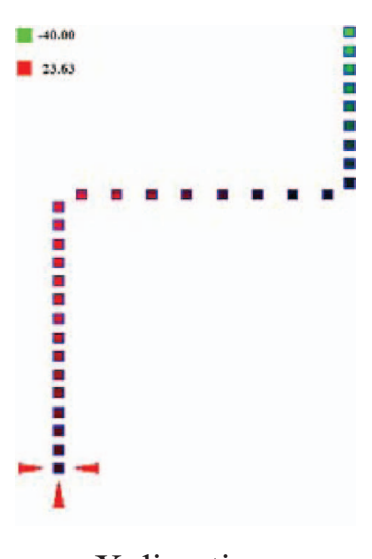

$\mathrm{X}$ direction

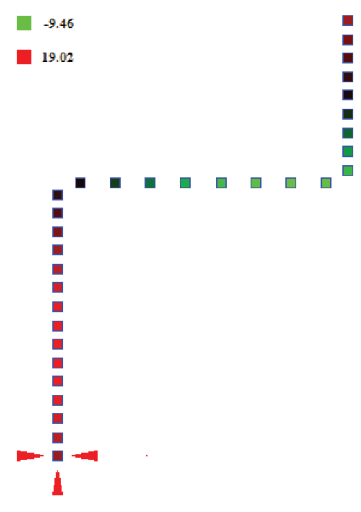

$\mathrm{X}$ direction

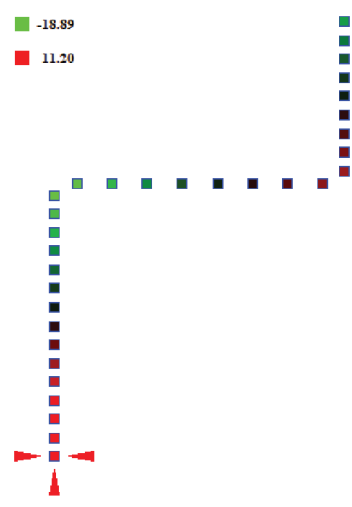

$\mathrm{X}$ direction

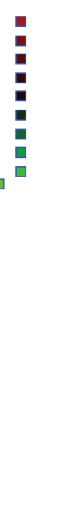

a. 132

- 1934

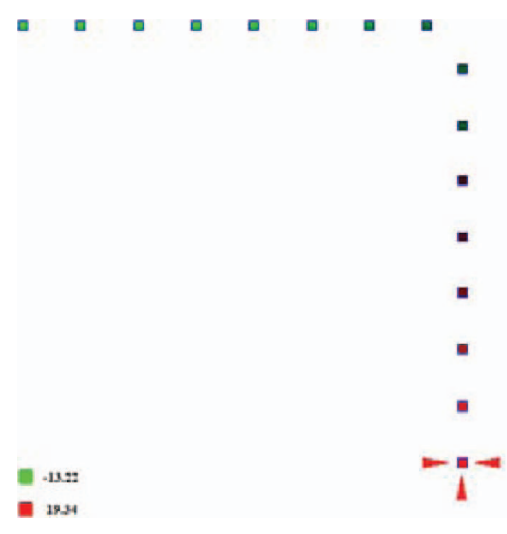

Y direction

ODS AT 293 Hz

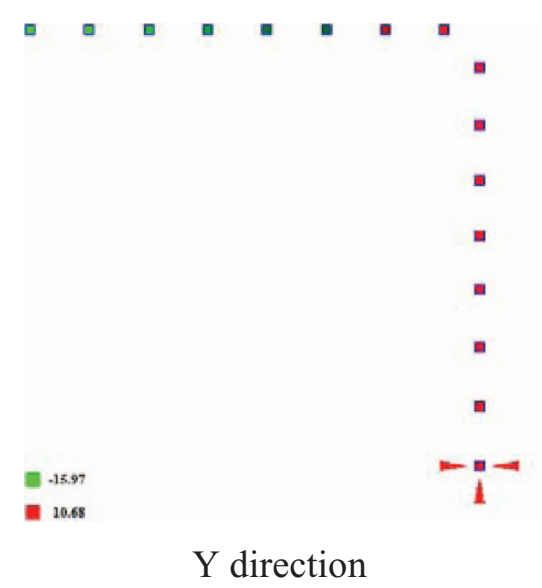

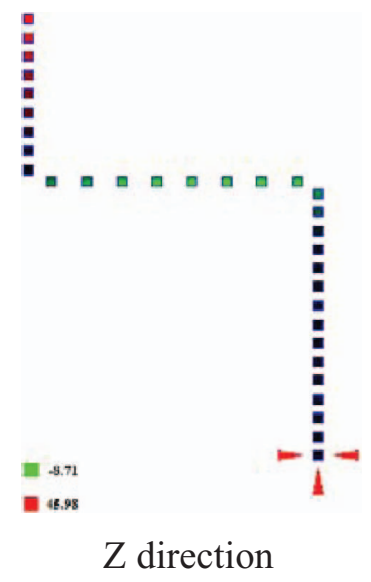
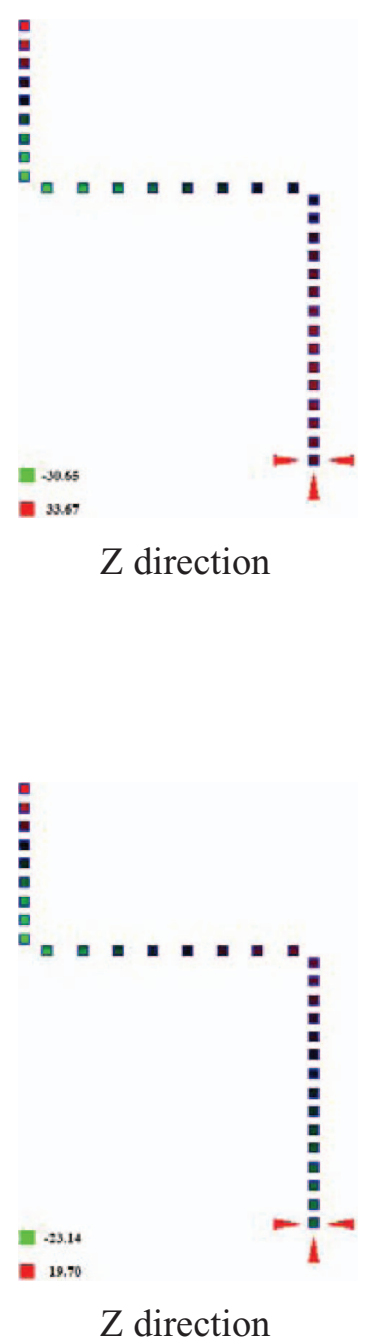


\section{APPENDIX C: ODSS MEASURED USING 6DOF SCANNER}

ODS AT $91 \mathrm{~Hz}$

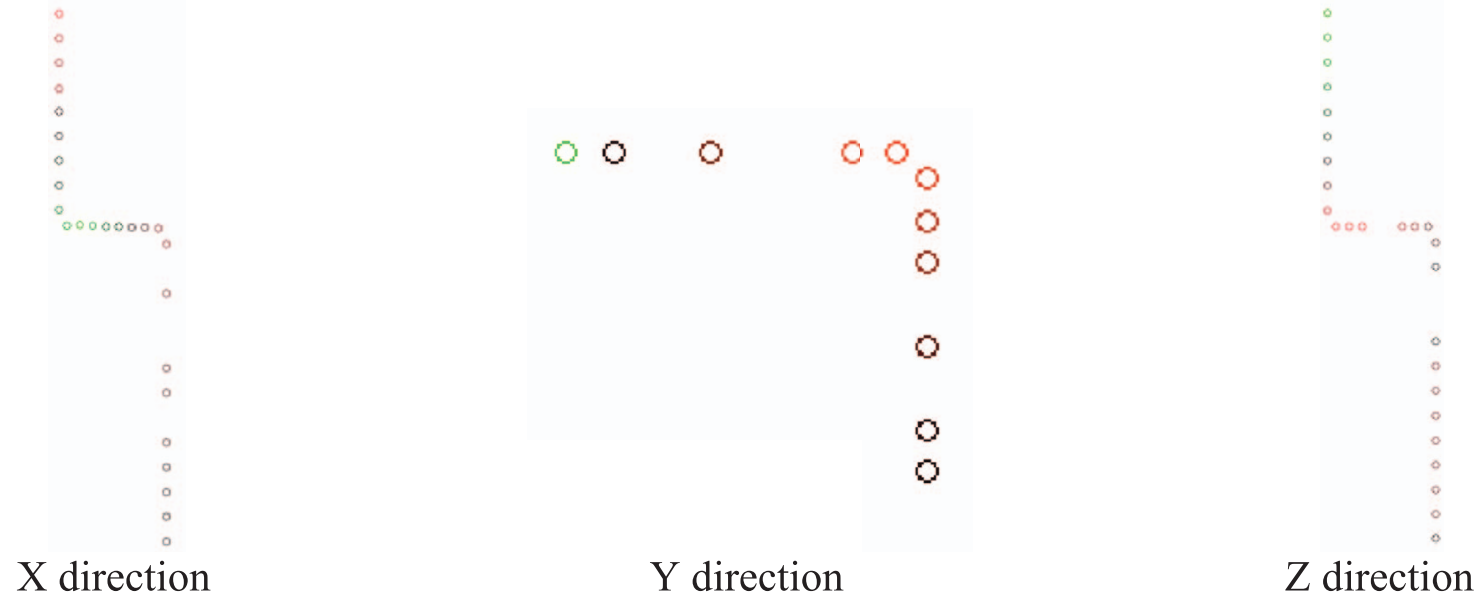

\section{ODS AT $130 \mathrm{~Hz}$}
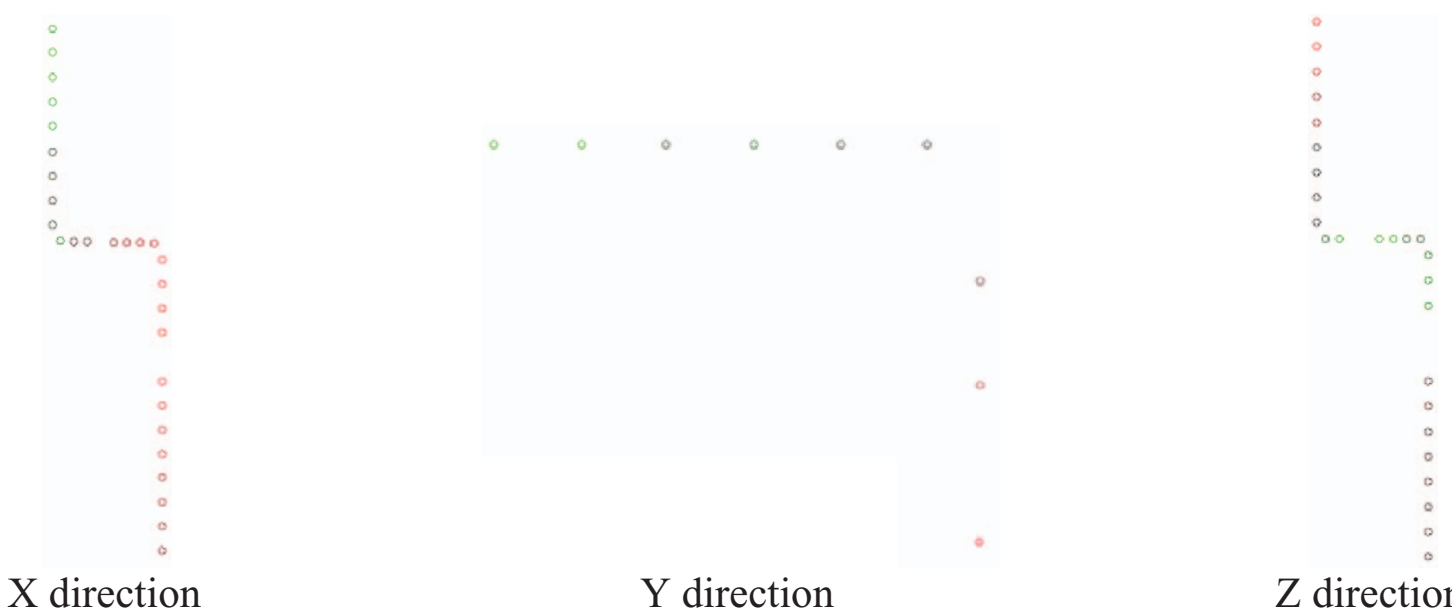

${ }^{1}$ J. Tyson, "Full-field vibration and strain measurement [ESPI]," Sensors 16(6), 16 (1999).

${ }^{2}$ C. Warren, C. Niezrecki, P. Avitabile, and P. Pingle, "Comparison of FRF measurements and mode shapes determined using optically image based, laser, and accelerometer measurements," Mech. Syst. Signal Process. 25(6), 2191-2202 (2011).

${ }^{3}$ M. N. Helfrick, C. Niezrecki, P. Avitabile, and T. Schmidt, "3D digital image correlation methods for full-field vibration measurement," Mech. Syst. Signal Process. 25(3), 917-927 (2011).

${ }^{4}$ W. Wang, J. E. Mottershead, T. Siebert, and A. Pipino, "Frequency response functions of shape features from full-field vibration measurements using digital image correlation," Mech. Syst. Signal Process. (28), 333-347 (2012).
${ }^{5}$ A. B. Stanbridge and D. J. Ewins, "Measurement of translational and angular vibration using a scanning laser Doppler vibrometer," Proc. SPIE 2358, 37 (1994).

${ }^{6}$ A. B. Stanbridge and D. J. Ewins, "Measurement of total vibration at a point using a conical-scanning LDV," Proc. SPIE 2868, 126-136 (1996).

${ }^{7}$ A. B. Stanbridge and D. J. Ewins, "Modal testing using a scanning laser Doppler vibrometer," Mech. Syst. Signal Process. 13(2), 255-270 (1999).

${ }^{8}$ P. Giuliani, D. Di Maio, C. W. Schwingshackl, M. Martarelli, and D. J. Ewins, "Six degrees of freedom measurement with continuous scanning laser Doppler vibrometer," Mech. Syst. Signal Process. 38, 367-383 (2013).

${ }^{9}$ ICATS, modal analysis software, ICON Suite, 58 Prince's Gate Exhibition Road, London.

${ }^{10}$ D. Di Maio, C. Schwingshakl, P. Giuliani, and D. J. Ewins, AIP Conf. Proc. 1457, $242(2012)$ 